\title{
Urea-Formaldehyde Foam
}

\section{Insulations: A Review of Their}

Properties and Performance

Walter J. Rossiter, Jr. and Robert G. Mathey

NBS NBS NBS NBS NBS NBS NBS NBS NBS NBS iS NBS NBS NBS NBS NBS NBS NBS NBS NBS NB. NBS NBS NBS NBS NBS NBS NBS NBS NBS NBS iS NBS NBS NBS NBS NBS NBS NBS NBS NBS NB. NBS NBS NBS NBS NBS NBS NBS NBS NBS NBS iS NBS NBS NBS NBS NBS NBS NBS NBS NBS NB. NBS NBS NBS NBS NBS NBS NBS NBS NBS NBS iS NBS NBS NBS NBS NBS NBS NBS NBS NBS NB. NBS NBS NBS NBS NBS NBS NBS NBS NBS NBS iS NBS NBS NBS NBS NBS NBS NBS NBS NBS NB. NBS NBS NBS National Bureau of Standards NBS NBS iS NBS NBS NBS NBS NBS NBS NBS NBS NBS NB: NBS NBS NBS NBS NBS NBS NBS NBS NBS NBS ac $\quad B S N B S N B S N B S N B S N B S N B S$ NBS NBS NB. $100 \quad N B S$ NBS NBS NBS NBS NBS NBS NBS NBS .05753
No. 1210 1985 c. 2 
he National Bureau of Standards ${ }^{1}$ was established by an act of Congress on March 3, 1901. The Bureau's overall goal is to strengthen and advance the nation's science and technology and facilitate their effective application for public benefit. To this end, the Bureau conducts research and provides: (1) a basis for the nation's physical measurement system, (2) scientific and technological services for industry and government, (3) a technical basis for equity in trade, and (4) technical services to promote public safety. The Bureau's technical work is performed by the National Measurement Laboratory, the National Engineering Laboratory, the Institute for Computer Sciences and Technology, and the Center for Materials Science.

\section{The National Measurement Laboratory}

Provides the national system of physical and chemical measurement; coordinates the system with measurement systems of other nations and furnishes essential services leading to accurate and uniform physical and chemical measurement throughout the Nation's scientific community, industry, and commerce; provides advisory and research services to other Government agencies; conducts physical and chemical research; develops, produces, and distributes Standard Reference Materials; and provides calibration services. The Laboratory consists of the following centers:
- Basic Standards ${ }^{2}$

- Radiation Research

- Chemical Physics

- Analytical Chemistry

\section{The National Engineering Laboratory}

Provides technology and technical services to the public and private sectors to address national needs and to solve national problems; conducts research in engineering and applied science in support of these efforts; builds and maintains competence in the necessary disciplines required to carry out this research and technical service; develops engineering data and measurement capabilities; provides engineering measurement traceability services; develops test methods and proposes engineering standards and code changes; develops and proposes new engineering practices; and develops and improves mechanisms to transfer results of its research to the ultimate user. The Laboratory consists of the following centers:
- Applied Mathematics

- Electronics and Electrical Engineering ${ }^{2}$

- Manufacturing Engineering

- Building Technology

- Fire Research

- Chemical Engineering 2

\section{The Institute for Computer Sciences and Technology}

Conducts research and provides scientific and technical services to aid Federal agencies in the selection, acquisition, application, and use of computer technology to improve effectiveness and economy in Government operations in accordance with Public Law 89-306 (40 U.S.C. 759), relevant Executive Orders, and other directives; carries out this mission by managing the Federal Information Processing Standards Program, developing Federal ADP standards guidelines, and managing Federal participation in ADP voluntary standardization activities; provides scientific and technological advisory services and assistance to Federal agencies; and provides the technical foundation for computer-related policies of the Federal Government. The Institute consists of the following centers:
- Programming Science and Technology

- Computer Systems Engineering

\section{The Center for Materials Science}

Conducts research and provides measurements, data, standards, reference materials, quantitative understanding and other technical information fundamental to the processing, structure, properties and performance of materials; addresses the scientific basis for new advanced materials technologies; plans research around cross-country scientific themes such as nondestructive evaluation and phase diagram development; oversees Bureau-wide technical programs in nuclear reactor radiation research and nondestructive evaluation; and broadly disseminates generic technical information resulting from its programs. The Center consists of the following Divisions:
- Inorganic Materials

- Fracture and Deformation ${ }^{3}$

- Polymers

- Metallurgy

- Reactor Radiation 


\section{Urea-Formaldehyde Foam Insulations: A Review of Their Properties and Performance}

Walter J. Rossiter, Jr.

Robert G. Mathey

Center for Building Technology National Engineering Laboratory National Bureau of Standards

Gaithersburg, MD 20899
Sponsored by:

Office of Conservation and

Renewable Energy

Department of Energy

1000 Independence Ave., S.W.

Washington, DC 20585

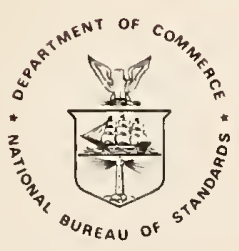

U.S. Department of Commerce Malcolm Baldrige, Secretary National Bureau of Standards Emest Ambler, Director 
National Bureau of Standards

Technical Note 1210

Natl. Bur. Stand. (U.S.),

Tech. Note 1210 .

70 pages (Mar. 1985)

CODEN: NBTNAE
U.S. Government Printing Office Washington: 1985
For sale by the Superintendent of Documents.

U.S. Government Printing Office. Washington, DC 20402 


\section{ABSTRACT}

Urea-formaldehyde foam insulation was commonly used in the mid-to-1ate $1970 \mathrm{~s}$ for retrofitting the sidewalls of residences. Many reports describing the use of this material in buildings have been published. This report presents a review of the properties and performance of urea-formaldehyde foams pertinent to their use as thermal insulation for buildings. The review is based primarily on existing published literature. The factors affecting the performance of these insulations are listed and discussed. Included among these factors are durability, effect on energy conservation, effect on other building materials, fungus resistance, shrinkage, and temperature and humidity effects on foam.

A key issue involving the use of urea-formaldehyde foam insulation is its release of formaldehyde, other gases, and particulates into the air of residences. Information concerning the release of these agents is summarized. The literature evidence indicates that where formaldehyde measurements have been made, on the average, formaldehyde levels in homes with foam insulation are higher than those without foam. The mechanism of formaldehyde release from foams is not totally understood. A review of remedial actions which may be taken to reduce or eliminate formaldehyde release from foams into residences is given. The information concerning the remedial actions discussed are those primarily being used in Canada. In addition, standards for urea-formaldehyde foam insulations developed in North America and Europe were reviewed and the material property requirements tabulated. The standards do not contain requirements pertaining to the long-term release of formaldehyde from these foam insulations.

Key words: Cellular plastics; energy conservation; formaldehyde; performance factors; remedial actions; retrofit; standards; thermal insulation; urea-formaldehyde foam. 
1. INTRODU CTION $\ldots \ldots \ldots \ldots \ldots \ldots \ldots \ldots \ldots \ldots \ldots \ldots \ldots \ldots \ldots \ldots \ldots \ldots \ldots \ldots \ldots$

1.1 Background $\ldots \ldots \ldots \ldots \ldots \ldots \ldots \ldots \ldots \ldots \ldots \ldots \ldots \ldots \ldots \ldots \ldots \ldots \ldots$

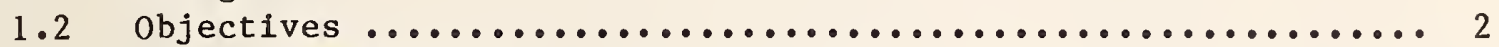

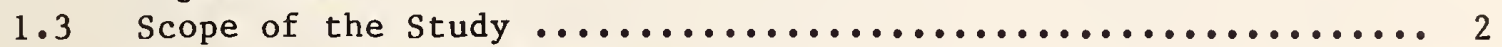

1.4 Urea-Formaldehyde Foam Insulation $\ldots \ldots \ldots \ldots \ldots \ldots \ldots \ldots \ldots$

2. STANDARDS AND USE OF FOAM IN OTHER COUNTRIES $\ldots \ldots \ldots \ldots \ldots \ldots \ldots \ldots \ldots$

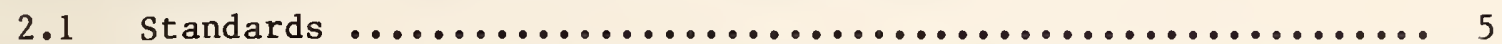

2.2 Adequacy of Standards for Predicting Formaldehyde Release .... 8

2.3 Use of Urea-Formaldehyde Foam Insulation in Other Countries .. 8

3. FACTORS AFFECTING THE PERFORMANCE OF UREA-FORMALDEHYDE FOAM

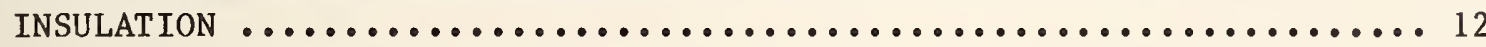

3.1 Areas of Application $\ldots \ldots \ldots \ldots \ldots \ldots \ldots \ldots \ldots \ldots \ldots \ldots \ldots \ldots$

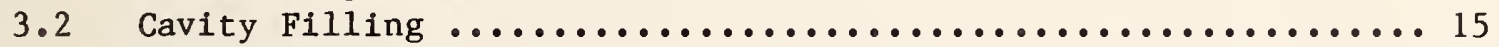

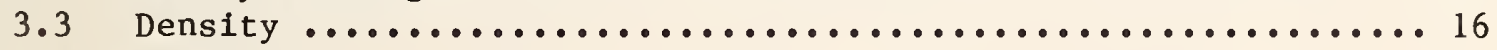

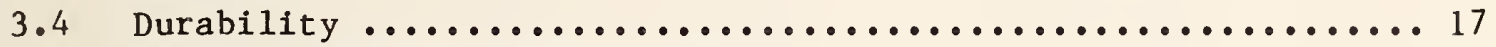

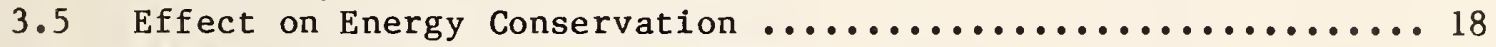

3.6 Effect un Other Building Materials ..................... 19

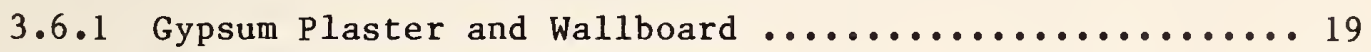

3.6 .2 Masonry Materials and Mortar ................... 20

3.6 .3 Metals ................................... 20

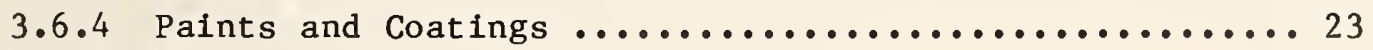

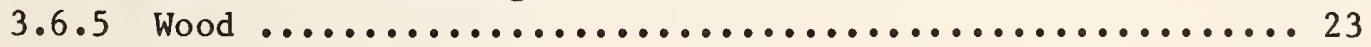

3.7 Electrical Properties ............................ 25

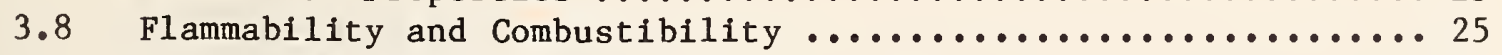

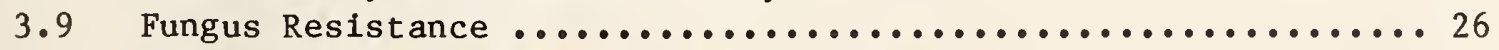

3.10 Offgassing and Release of Particulates ................. 28

3.11 Quality Control of Component Materials .................. 28

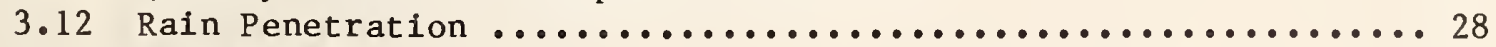

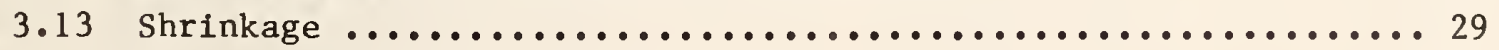

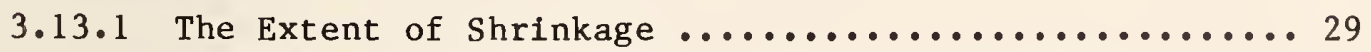

3.13.2 The Effect of Shrinkage on Thermal Performance ...... 30

3.14 Temperature and Humidity Effects on Foam ................ 32

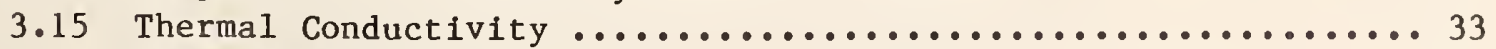

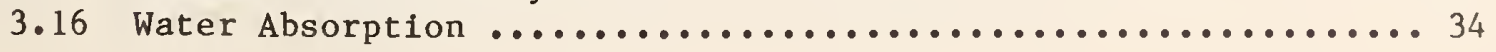


4. RELEASE OF FORMALDEHYDE, OTHER GASES, AND PARTI CULATES ........ 36

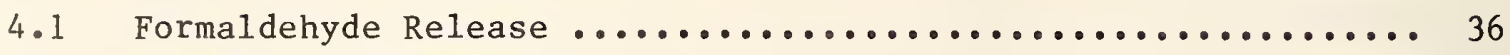

4.1 .1 Formaldehyde Levels in Residences ............... 36

4.1 .2 Formaldehyde Measurement ..................... 38

4.1 .3 Mechanism of Formaldehyde Release ............... 40

4.1.4 Effects of Application Parameters on Formaldehyde

Release .............................. 41

4.1.5 Formaldehyde Release and Standards for Urea-

formaldehyde Foams ........................ 41

4.2 Release of Gases other Than Formaldehyde .............. 42

4.3 Release of Particulates ......................... 42

5. REMEDIAL MEASURES ................................ 43

5.1 Present Practices ............................ 43

5.1 .1 Problem Identification ....................... 44

5.1.2 Understanding the Nature of Urea-formaldehyde Foam

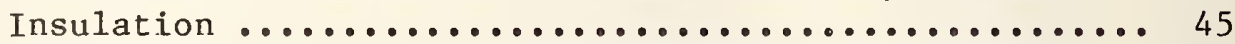

5.1.3 Understanding Air and Vapor Movement in Residences .... 45

5.1 .4 Knowledge of the Type of Construction ............ 46

5.1 .5 Types of Remedial Measures .................... 46

5.2 Effectiveness of Remedial Actions .................. 47

5.3 Research on Urea-Formaldehyde Foam Insulation ............ 48

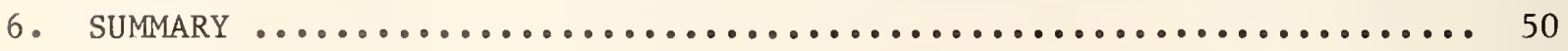

7. REFERENCES ................................................ 54

8. ACKNOWLEDGEMENTS ..................................... 64 


\section{INTRODU CTION}

\subsection{BACKGROUND}

Prior to 1973, energy costs were low and 1ittle attention was paid to effective use of energy in homes [1]. Many residences were constructed without being adequately insulated in the ceilings, walls, and floors. As energy costs began to rise, it became apparent that retrofitting residences for energy conservation through the addition of insulation, storm windows and doors, and other measures was cost-effective for homeowners [2]. One estimate in 1973 indicated that effective retrofitting could save about 20 percent of the energy used for residential heating and cooling in the United states [3].

A thermal insulation which came into popular use in the mid - 1970s was ureaformaldehyde foam. It has been estimated that approximately 500,000 residences were insulated with this foam in the United States [4]. Urea-formaldehyde foam insulation was most commonly used for retrofitting the exterior cavity walls of existing residential constructions. Less commonly, it was used for new residential construction and also for new and existing commercial and industrial buildings.

When the use of urea-formaldehyde foam insulation increased in the United States, guidelines were not available for its evaluation. In the mid - 1970s, much of the information published in the literature concerning performance was contradictory [5]. Until 1981, a voluntary consensus standard to aid in the selection of these foams was not available in the United States. In 1977 , the National Bureau of Standards published Technical Note 946, "Urea-Formaldehyde Based Foam Insulations: An Assessment of Their Properties and Performance." This early publication reviewed and summarized existing information concerning the performance and application practices for these foams [5]. It was reported that among other considerations the insulation was relatively easy to install. A major concern at that time was that some material and performance properties had not been adequately determined for the foams.

A key issue involving the use of urea-formaldehyde foam insulations has been the release of formaldehyde. As the use of the insulation grew in the late 1970s, consumers' complaints concerning formaldehyde release increased [6]. Because of concerns of adverse effects on the health of building occupants exposed to formaldehyde emitted from foams, a ban on its use in residences and schools as thermal insulation was enacted in the United states [7]. This ban, promulgated by the Consumer Product Safety Commission (CPSC), was effective on August 10, 1982, but was set aside on judicial review during the summer of 1983 [8]. Since the national ban on urea-formaldehyde foam insulation was set aside, installation of the foam could again be carried out in the United States except where state or local restrictions apply [8]. Connecticut and Massachusetts are states where the installation of foam is not allowed. A ban on ureaformaldehyde foam insulation for use in buildings as thermal insulation has been in effect in Canada since December 18, 1980 [9].

Since information concerning foam performance as a thermal insulation was last reviewed in the United States in 1977, many additional reports have been 
published. This additional information has not been the subject of a review. Although much of this additional information centered around the release of formaldehyde from foams, other important performance properties including shrinkage, corrosiveness to metals, moisture effects, and fungus resistance have also been addressed in the 1iterature. In addition, recent information is available, primarily from Canada, as to steps which may be taken as remedial actions to assist in alleviating or solving problems of formaldehyde release from foams into the air space of residences. Thus, the U.S. Department of Energy (DOE) requested the U.S. National Bureau of Standards (NBS) to review the state-of-the art of urea-formaldehyde foam insulation. This report presents the results of the review.

\subsection{OBJECTIVES}

The objectives of this report are:

(1) to list standards which have been developed for urea-formaldehyde foam insulations and to present requirements for materials properties given in the standards;

(2) to review current information concerning the properties and performance of urea-formaldehyde foam insulations; and

(3) to review information concerning remedial actions for reducing or eliminating formaldehyde release from foams into residences.

\subsection{SCOPE OF THE STUDY}

The study was limited to a review of the use of urea-formaldehyde foam as a thermal insulation. Included in the review was a summary of information concerning formaldehyde release from foam insulations. Since medical expertise resides outside of NBS, potential health effects associated with the release of formaldehyde or other gases and particulates from foams was beyond the scope of the study. In the United States, the Consumer Product Safety Commission studied the potential health effects associated with foams [7].

As requested by DOE, the review of the properties and performance of ureaformaldehyde foam insulations was based upon existing information. Laboratory investigations were not conducted as part of this study. The reports and other documents reviewed in the study were generally published after 1976, since information published prior to that year was reviewed by NBS in 1977 [5]

A major source of information for the review was the chemical and engineering literature. Another source was building research organizations in foreign countries where research has been conducted on foam performance. Discussions were held with building researchers knowledgeable in the performance of urea-formaldehyde foam insulations. The information obtained included standards for foam insulations, comments on the use of foam in foreign countries, reports on foam properties and performance, and documents describing remedial actions regarding formaldehyde release from foams. The major findings of the review of the information obtained in this study are summarized in section 6 . 


\subsection{UREA-FORMALDEHYDE FOAM INSULATION}

As a building insulation, urea-formaldehyde foam is generated on-site using portable equipment. A partially polymerized urea-formaldehyde resin is mechanically foamed and then reacts chemically (cures) in place. The chemistry of urea-formaldehyde resins has been reviewed by Meyer [10].

Three major ingredients are used in the generation of the foam: urea-formaldehyde resin, a surfactant (generally called a foaming agent) which includes an acid catalyst or hardening agent, and air. In general, three types of resin systems have been used to produce the foams on-site. In one, the urea-formaldehyde resin is transported to the job site as an aqueous solution. In another, the resin is brought to the job site as a powder and mixed with water on-site. In the third, the resin is brought to the job site as a concentrated solution where it is diluted with water prior to application.

The equipment for generating the foam generally consists of a compressed air pump and a mixing or foaming gun. In the United States the foaming agentcatalyst mixture is in general pumped into the gun where compressed air mixes with it and mechanjcally expands it into foam consisting of small bubbles. The bubbles are then coated in the nozzle of the gun with the urea-formaldehyde resin which has been pumped through a separate line into the gun. The foam, consisting of resin coated bubbles, is forced out of the gun under pressure at which time it contains about 75 percent water by weight. The water is present because the resin and foaming agent were mixed together for chemical reaction as aqueous solutions.

The technique for foam generation in the U.S. has also been used in Europe in addition to other methods. As one example, both resin and the foaming agent solutions are mixed through the expansion chamber of the gun. In another, the catalyst is added to the foam after initial expansion.

After the urea-formaldehyde resin mixes with the catalyst on the surface of the foam bubbles, the resin immediately begins to cure. The resin coated bubbles exit from the nozzle of the gun as a fully expanded lather which has a consistency typically described as resembling foam shaving cream. Normally, within less than a minute after leaving the gun, the resin has partially cured into a stiff, self-supporting foam. Complete chemical curing of the foam generally occurs within weeks after application. The rate of chemical curing is dependent upon factors such as temperature and foam formulation. The water, present initially during foaming, dries out at a rate which is dependent upon temperature, humidity, foam formulation, and the type of construction to which the foam is applied.

Although urea-formaldehyde foam insulation has been considered a generic material, there are differences in composition and properties of the various foams which have been available. Additives, fillers, extenders, and plasticizers have been added to foam in attempts to improve or alter some of its properties such as to reduce shrinkage, raise $\mathrm{pH}$, and mask odors. 
Because this insulation is generated on-site, the composition of a given foam in a residence may vary considerably, particularly if application parameters for proper installation are not controlled [11]. Examples of application parameters requiring control include separation of the resin (in an aqueous solution) in the transportation drum, localized contaminants in the drums, changes in temperature before mixing in the gun, changes in mixing efficiency or mixing ratio (in the extreme, a failure of one component to flow at al1), and the drying rate of the foam [11]. Because of the importance of proper application on foam performance, the U.S. Department of Energy had proposed for the Residential Conservation Service (RCS) Program equipment requirements for on-site foam generation [12]. These proposed requirements included the use of equipment that: was capable of automatically recirculating and agitating resins and foaming agents to maintain uniformity of components during installation; used compressed bottled gas in place of air compressors; and was also capable of automatic shut down within 10 seconds if a drop in regulated pressure occurred or if a 20 percent change in component ratios took place. Reports have not been published concerning the effectiveness of these proposed equipment requirements to control the quality of the installed foam. Since urea-formaldehyde foams were eliminated from the RCS Program, the equipment requirements were never put into effect.

The potential wide variability in foam composition within a given residence has significance regarding sampling that may be done to remove or observe test specimens in residences. Limited observations of foam in a small section of a wall may not be representative of the foam throughout the residence. 


\section{STANDARDS AND USE OF FOAM IN OTHER COUNTRIES}

\subsection{STANDARDS}

Standards for urea-formaldehyde foam insulation were reviewed with regard to their requirements pertaining to material and performance properties. The review included foreign standards and those developed in the United States. These documents were from Canada [13], the Netherlands [14], the United Kingdom [15], West Germany [16], and three from the United States [17, 18, 19]. The three United States standards were issued by ASTM [17], DOE [18], and the U.S. Department of Housing and Urban Development (HUD) [19]. These material standards specify values for the material and performance properties required of the foams and in general give test methods used to measure these values.

A synopsis of the material and performance properties of the urea-formaldehyde foam insulations given in these standards is presented in table 1 . It is evident from this table that certain properties of the foams are not included in all of the documents. The standard developed in Canada and the three from the United States are similar.

In most cases for the countries noted above, standards, guidelines, or requirements for foam application were developed in addition to the cited materials specifications. Application standards have been issued in Canada [20], the United Kingdom [21], and the United States [22]. The Canadian application standard [20] and the DOE application standard [22] were termed as provisional and interim, respectively. The West German material standard [16] includes requirements for installation, and the Netherlands [14] and HUD [19] documents give guidelines for proper application. An application standard has not been issued in the United States by the ASTM. A draft was in the early stage of preparation by an ASTM task group when the CPSC ban [7] was enacted, and little activity has occurred since that time. In all application documents, proper installation of urea-formaldehyde foam is emphasized and considered essential to obtain the foam properties as stated in the material standards.

Because of problems associated with the release of formaldehyde from foams, in North America many of the standards have been withdrawn including the Canadian material [13] and application standards [20], the DOE material [18] and application standards [22] and the HUD bulletin [19]. It is noted that the primary organization in Canada to use the Canadian material standard was the Canadian Mortgage and Housing Corporation (CMHC) for acceptance of foam in its insulation programs. The CMHC also imposed restrictions concerning the types of cavities into which foam could be installed in its programs.

In North America, the standards (ASTM, Canadian, DOE, and, HUD) permitted the use of urea-formaldehyde foam insulation in most typical residential exterior walls including wood frame and masonry. In contrast, in European countries, foam insulation is normally used in, and often restricted to, masonry cavitywall construction, although it has been used in other applications. The standards from the Netherlands [14] and from the United Kingdom [15] specify a restriction on the use of foam to masonry cavity walls. A proposed change to the West 
Table 1. Synopsis of the Material and Ferformance Froperties of Urea-Formaldehyde Foam Thermal Insulations Given in Poreign and United States Standards

\begin{tabular}{|c|c|c|c|c|c|c|c|}
\hline \multirow[b]{2}{*}{$\begin{array}{l}\text { Material or } \\
\text { Ferformance } \\
\text { Froperty }\end{array}$} & \multicolumn{7}{|c|}{ Standards for Urea-Formaldehyde Foam Thermal Insulation and Country of origin } \\
\hline & $\begin{array}{c}\text { Canada } \\
51 \mathrm{GF}-24 \mathrm{M} \\
{[13]} \\
\end{array}$ & $\begin{array}{c}\text { The Netherlands } \\
\text { Quality } \\
\text { Requirement } \\
\text { [14] }\end{array}$ & $\begin{array}{l}\text { The United Kingdom } \\
\text { BS } 5617: 1978 \\
{[15]}\end{array}$ & $\begin{array}{c}\text { United States } \\
\text { ASTM C951-83 } \\
{[17]}\end{array}$ & $\begin{array}{l}\text { United States } \\
\text { DOE RCS } \\
{[18]} \\
\end{array}$ & $\begin{array}{c}\text { United States } \\
\text { HUD UMB } 74 \\
{[19]}\end{array}$ & $\begin{array}{c}\text { West Germany } \\
\text { DiN } 18159 \\
\text { Part } 2 \\
{[16]}\end{array}$ \\
\hline Density & $\begin{array}{l}0.651 \mathrm{bm} / \mathrm{ft}^{3} \\
\left(10.4 \mathrm{~kg} / \mathrm{m}^{3}\right) \text { min1 mum }\end{array}$ & $\begin{array}{l}0.62 \mathrm{1bm} / \mathrm{ft}^{3} \\
\left(10.6 \mathrm{~kg} / \mathrm{m}^{3}\right) \text { minimum }\end{array}$ & - & $\begin{array}{l}\text { Dry - between } 0.7 \\
\text { and } 1.61 \mathrm{bm} / \mathrm{ft}^{2}(11 \\
\left.\text { and } 26 \mathrm{~kg} / \mathrm{m}^{3}\right) \text {; wet }- \\
\text { between } 2.5 \text { and } 5.5 \\
1 \mathrm{bm} / \mathrm{ft}^{3}(40 \text { and } 88 \\
\left.\mathrm{kg} / \mathrm{m}^{3}\right)\end{array}$ & $\begin{array}{l}\text { Not less than } 0.65 \\
1 \mathrm{bm} / \mathrm{ft} \mathrm{t}^{2}\left(10.4 \mathrm{~kg} / \mathrm{m}^{2}\right. \\
\text { for dry foam; manu- } \\
\text { facturer to specify } \\
\text { wet density } 11 \mathrm{mits}\end{array}$ & $\begin{array}{l}\text { Dry foam with the } \\
\text { range of } 0.65 \text { to } \\
0.941 \mathrm{bm} / \mathrm{ft}^{3} \text { (10.4 } \\
\left.\text { to } 15 \mathrm{~kg} / \mathrm{m}^{3}\right)\end{array}$ & $\begin{array}{l}\text { Dry foam bulk } \\
\text { density not less } \\
\text { than } 0.62 \text { l } \mathrm{bm} / \mathrm{ft}^{3} \\
\left(10 \mathrm{~kg} / \mathrm{m}^{3}\right)\end{array}$ \\
\hline $\begin{array}{l}\text { Thermal Resistance/ } \\
\text { Thermal Conductivity }\end{array}$ & $\begin{array}{l}\text { Not less than } \\
12 \mathrm{ft}^{2} \cdot \mathrm{h} \cdot{ }^{\circ} \mathrm{P} / \mathrm{Btu} \\
\left(2.2 \mathrm{~m}^{2} \cdot{ }^{\circ} \mathrm{C} / \mathrm{w}\right)\end{array}$ & -- & $\begin{array}{l}0.24 \mathrm{Btu} \cdot \mathrm{fn} / \mathrm{h} \cdot \mathrm{ft}^{2} \cdot{ }^{\circ} \mathrm{F} \\
(0.035 \mathrm{~W} / \mathrm{m} \cdot \mathrm{K}) \\
\text { maxi mum }\end{array}$ & $\begin{array}{l}\text { Test results should } \\
\text { be reported; values } \\
\text { may be obtained from } \\
\text { the manufacturer }\end{array}$ & $\begin{array}{l}\text { For any given spec1- } \\
\text { men, thermal resis- } \\
\text { tsnce should not } \\
\text { be more than } 5 \% \\
\text { below the average } \\
\text { value of resistances } \\
\text { of foam specimens } \\
\text { tested }\end{array}$ & $\begin{array}{l}\text { Not less than } 12 \\
\mathrm{ft} \mathrm{t}^{2} \cdot \mathrm{hr} \cdot{ }^{\circ} \mathrm{F} / \mathrm{Bcu}(2.2 \\
\left.\mathrm{m}^{2} \cdot{ }^{\circ} \mathrm{C} / \mathrm{w}\right)\end{array}$ & $\begin{array}{l}0.24 \mathrm{Btu} \cdot 1 \mathrm{n} / \mathrm{h} \cdot \mathrm{ft}^{2} \cdot{ }^{\circ} \mathrm{F} \\
(0.034 \mathrm{~W} / \mathrm{m} \cdot \mathrm{K}) \\
\max 1 \text { mum }\end{array}$ \\
\hline $\begin{array}{l}\text { Effective Thermal } \\
\text { Resistance/Effective } \\
\text { Thermal Conductivity }\end{array}$ & $\begin{array}{l}60 \% \text { of that for a } \\
\text { laboratory specimen, } \\
\text { and } 70 \% \text { of labora- } \\
\text { tory value for } \\
\text { cavities containing } \\
\text { mineral fiber batts }\end{array}$ & $\begin{array}{l}\text { Must not exceed } \\
0.35 \mathrm{Btu} \cdot 1 \mathrm{n} / \mathrm{h} \cdot \mathrm{ft}^{2} \cdot{ }^{\circ} \mathrm{F} \\
(0.050 \mathrm{~W} / \mathrm{m} \cdot \mathrm{K}) \text { in a } \\
\text { test wall, and must } \\
\text { not increase by more } \\
\text { than } 10 \% \text { during rain } \\
\text { teat }\end{array}$ & $\begin{array}{l}\text { For design purposes } \\
0.28 \mathrm{Btu} \cdot \mathrm{An} / \mathrm{h} \cdot \mathrm{ft}^{2} \cdot{ }^{\circ} \mathrm{F} \\
(0.04 \mathrm{~W} / \mathrm{m} \cdot \mathrm{K})\end{array}$ & $\begin{array}{l}\text { Due to shrinkage, } \\
\text { the thermal perfor- } \\
\text { wance of an assembly } \\
\text { may be different } \\
\text { than laboratory } \\
\text { measurements of the } \\
\text { foam }\end{array}$ & $\begin{array}{l}\text { Computed as } 70 \% \text { of } \\
\text { laboratory value, } \\
\text { this value should } \\
\text { be reported to the } \\
\text { public }\end{array}$ & $\begin{array}{l}\text { If expected shrink- } \\
\text { age over two years } \\
\text { not establlshed, } \\
\text { computed as } 72 \% \text { of } \\
\text { laboratory value; 1f } \\
\text { shrinkage over two } \\
\text { years established, } \\
\text { calculate reduction } \\
\text { factor }\end{array}$ & - \\
\hline $\begin{array}{l}\text { Shrinkage - Iinear } \\
\text { In a test cavity }\end{array}$ & $\begin{array}{l}4 \% \text { maximum after } \\
28 \text { days }\end{array}$ & $\begin{array}{l}7 \% \text { maximum after } \\
\text { dry1 ng at } 77^{\circ} \mathrm{F} \\
\left(25^{\circ} \mathrm{C} \text { and } 40 \% \mathrm{RH}\right. \\
\text { to constant mass }\end{array}$ & $\begin{array}{l}8 \% \text { maximum after } \\
\text { drying at } 73^{\circ} \mathrm{F} \\
\left(23^{\circ} \mathrm{C}\right) \text { and } 63 \% \mathrm{RH} \\
\text { to constant mass; } \\
\text { for quality control, } \\
10 \% \text { maximum under } \\
\text { external amblent } \\
\text { conditions for } \\
21 \text { daygc/ }\end{array}$ & $\begin{array}{l}4 \% \text { maximum af ter } \\
\text { f resh foam has } \\
\text { cured at } 72^{\circ} \mathrm{F}\left(22^{\circ} \mathrm{C}\right) \\
\text { and } 50 \% \mathrm{RH} \text { to con- } \\
\text { stant weight }\end{array}$ & $\begin{array}{l}4 \% \text { maximum after } \\
\text { drying at } 74^{\circ} \mathrm{F} \\
\left(23^{\circ} \mathrm{C}\right) \text { and } 50 \% \mathrm{RH} \\
\text { for } 28 \text { days }\end{array}$ & $\begin{array}{l}4 \% \text { maximum af ter } \\
\text { dr - Ing at } 74^{\circ} \mathrm{F} \\
\left(23^{\circ} \mathrm{C}\right) \text { and } 50 \% \text { RH } \\
\text { for } 28 \text { days }\end{array}$ & $\begin{array}{l}\text { 4\% msximum sf ter } \\
\text { drying at } 68^{\circ} \mathrm{F} \\
\left(20^{\circ} \mathrm{C}\right) \text { for } 28^{\circ} \text { days }\end{array}$ \\
\hline Corrosiveness & $\begin{array}{l}\text { Corrosion rates less } \\
\text { than } 150 \mu \mathrm{m} / \mathrm{y} \text { for } \\
\text { steel, } 25 \mu \mathrm{m} / \mathrm{y} \text { for } \\
\text { copper and aluminum, } \\
\text { and } 90 \mu \mathrm{m} / \mathrm{y} \text { for } \\
\text { galvanized ateel } /\end{array}$ & $\begin{array}{l}\text { Galvanized steel } \\
\text { wall ties embedded } \\
\text { in foam must not } \\
\text { exh1bit more evi- } \\
\text { dence of corrosion } \\
\text { than ties not } \\
\text { embedded in foam }\end{array}$ & - & $\begin{array}{l}\text { Maximum allowsble } \\
\text { corrosion rates of } \\
6 \text { m1ls/y }(150 \mu \mathrm{m} / \mathrm{y}) \\
\text { for ateel, } 3.5(90) \\
\text { for galvanized 1 ron, } \\
\text { and } 1(25) \text { for copper } \\
\text { and aluminum }\end{array}$ & $\begin{array}{l}\text { Corrosion rates } \\
\text { ahould not exceed } \\
6 \mathrm{mils} / \mathrm{y}(0.15 \mathrm{~mm} / \mathrm{y}) \\
\text { for steel, } 3.5(0.09) \\
\text { for galvanized } \\
\text { steel, and } 1(0.025) \\
\text { for copper and } \\
\text { aluminum }\end{array}$ & $\begin{array}{l}\text { No perforations in } \\
\text { thin aluminum, } \\
\text { copper, and steel } \\
\text { specimens; no pit- } \\
\text { ting of galvantzed } \\
\text { steel and mass loss } \\
0.01 \text { oz }(0.2 \mathrm{~g}) \\
\text { maximum }\end{array}$ & $\begin{array}{l}\text { If testing is nec- } \\
\text { essary, test method } \\
\text { selected in coordin- } \\
\text { at lon with expert } \\
\text { test1ng agency. } \\
\text { Testing required } \\
\text { when aluminum parts } \\
\text { fllled with foamd }\end{array}$ \\
\hline $\begin{array}{l}\text { Fungal Growth } \\
\text { lnhibition }\end{array}$ & $\begin{array}{l}\text { No fungal growth on } \\
\text { fosm; ares of fung } \\
\text { in wood test frame } \\
\text { a maximum of } 10 z \text { of } \\
\text { that in control } \\
\text { frame }\end{array}$ & $\begin{array}{l}\text { Foam must be } \\
\text { resistant to attack } \\
\text { by mold }\end{array}$ & No microbial attack & $\begin{array}{l}\text { No test included; } \\
\text { fungal growth may } \\
\text { occur under molst } \\
\text { or humid conditions } \\
\text { on wood and the } \\
\text { foam; foam should } \\
\text { dry sa short a time } \\
\text { as possible }\end{array}$ & -- & $\begin{array}{l}\text { No fungal growth on } \\
\text { foam; area of fung1 } \\
\text { In wood test frame } \\
\text { a max } 1 \text { mum of } 10 \% \text { of } \\
\text { that in control } \\
\text { frame }\end{array}$ & $\begin{array}{l}\text { Must be resistant } \\
\text { to aging and may not } \\
\text { be blologically } \\
\text { usable (1.e., by } \\
\text { mold or fungus) }\end{array}$ \\
\hline $\begin{array}{l}\text { Free Formaldehyde } \\
\text { Content of Resin }\end{array}$ & $1 \%$ maximum by mass & Less than $1 \%$ by mass & $1 \%$ maximum by mass & $\begin{array}{l}\text { Free aldehydes in } \\
\text { resin; } 17 \text { by mass } \\
\text { maximum }\end{array}$ & $\begin{array}{l}\text { Maximum of } 0.5 \% \text { by } \\
\text { mass }\end{array}$ & $\begin{array}{l}\text { Maximum of } 1 \% \text { by } \\
\text { mass }\end{array}$ & - \\
\hline $\begin{array}{l}\text { Formaldehyde } \\
\text { Concentration in } \\
\text { fresh foam on a } \\
\text { test room }\end{array}$ & -- & $\begin{array}{l}\text { The mean release of } \\
\text { formaldehyde must } \\
\text { not exceed }(1000 \mathrm{mg} / \\
100 \mathrm{~g}) \text { of dry foam }\end{array}$ & - & $\begin{array}{l}\text { Pree aldehydes in } \\
\text { fosm; } 0.6 \% \text { by mass } \\
\text { maximum }\end{array}$ & $\begin{array}{l}\text { Maximum of } 0.3 \% \text { by } \\
\text { mass of fresh foam }\end{array}$ & - & $\begin{array}{l}\text { Not higher than } \\
6 \mathrm{ppm} \text { in } 40 \mathrm{~m}^{3} \text { test } \\
\text { room with } 1 \mathrm{n} \text { situ } \\
\text { foam (fresh) over } \\
336 \mathrm{~h} f\end{array}$ \\
\hline
\end{tabular}

a/ Applies exclusively to exterior walls of stone-like material.

b/ Amendment No. 2 (June 1979).

cf Measurements of clrcumference of a round sample.

d/ Flanned amendment or change No. 1 (September 1981). 
Table 1. Cont1nued

\begin{tabular}{|c|c|c|c|c|c|c|c|}
\hline & Standards for $U$ & Urea-Formaldehy de Foan & Thermal Insulation & and Country of Drigin & & & \\
\hline $\begin{array}{l}\text { Material or } \\
\text { Performance } \\
\text { Property }\end{array}$ & $\begin{array}{c}\begin{array}{c}\text { Canada } \\
\text { 51 GP-24 M } \\
{[13]}\end{array} \\
\end{array}$ & $\begin{array}{l}\text { The Netherlands } \\
\text { Quality } \\
\text { Requirementsa/ } \\
{[14]}\end{array}$ & $\begin{array}{c}\text { The United Kingdon } \\
\text { BS 5617: } 1978 \\
{[15]}\end{array}$ & $\begin{array}{c}\text { United States } \\
\text { ASTM C951-83 } \\
{[17]}\end{array}$ & $\begin{array}{c}\text { United States } \\
\text { DDE RCS } \\
{[18]}\end{array}$ & $\begin{array}{c}\text { United State } \\
\text { HUD UMB } 74 \\
{[19]}\end{array}$ & $\begin{array}{l}\text { West Germany } \\
\text { DIN } 18159 \\
\text { Part } 2 \\
{[16]}\end{array}$ \\
\hline $\begin{array}{l}\text { Volume Resistivity } \\
\text { of Fresh Foam }\end{array}$ & $\begin{array}{l}\text { Not less than } \\
(5 \mathrm{k} \Omega \cdot \mathrm{cm}) \text { within } 30 \mathrm{~s} \\
\text { af ter foaming }\end{array}$ & - & - & $\begin{array}{l}\text { Not less than } \\
5 \mathrm{k} \Omega \cdot \mathrm{cm} \text { within } 1 \\
\text { win af ter foaming }\end{array}$ & $\begin{array}{l}\text { Not less than } \\
(5 \mathrm{k} \Omega \cdot \mathrm{cm}) \text { for fresh } \\
\text { foam }\end{array}$ & $\begin{array}{l}\text { Not less than } \\
5 k .6 \mathrm{~cm}) \text { for fresh } \\
\text { foam }\end{array}$ & - \\
\hline Water Drainage & $\begin{array}{l}\text { No water will leak } \\
\text { f rom test cavity } \\
\text { with1n } 24 \text { a after } \\
\text { f oaming }\end{array}$ & - & - & $\begin{array}{l}\text { No water will leak } \\
\text { from the cavity } \\
\text { with1n } 24 \mathrm{~h} \text { after } \\
\text { foaming }\end{array}$ & $\begin{array}{l}\text { No water leakage } \\
\text { from plywood cavity } \\
\text { within } 24 \mathrm{~h} \text { after } \\
\text { foaming }\end{array}$ & $\begin{array}{l}\text { No water leakage } \\
\text { f rom cavity within } \\
24 \mathrm{~h} \text { after foaming }\end{array}$ & - \\
\hline Sett1ng Time & $\begin{array}{l}\text { Between } 20 \text { and } 90 \mathrm{~B}, \\
\text { leaving a smooth } \\
\text { homogeneous fracture }\end{array}$ & $\begin{array}{l}\text { Between } 20 \text { and } 60 \mathrm{~B}, \\
\text { may fluctuate due to } \\
\text { higher or lower } \\
\text { amblent temperatures }\end{array}$ & - & Between $10-60 \mathrm{~B}$ & Between $10-60$ s & $\begin{array}{l}\text { Between } 20-60 \text { s } \\
\text { in closed cavitles, } \\
\text { and between } 10-60 \text { s } \\
\text { in open cavities }\end{array}$ & Within 608 \\
\hline Water Absorption & $\begin{array}{l}15 \% \text { by volume maxi- } \\
\text { mum in } 7 \text { days; and } \\
\text { drops of methy } 1 \\
\text { violet solution not } \\
\text { absorbed within } 1 \mathrm{~h}\end{array}$ & $\begin{array}{l}\text { Foam cubes on water } \\
\text { must not Bink more } \\
\text { than } 0.39 \text { in. } \\
(10 \mathrm{~mm}) \text { within } 4 \\
\text { weeks }\end{array}$ & $\begin{array}{l}\text { Water absorbency of } \\
\text { foam prisms on water } \\
\text { for } 24 \mathrm{~h} \text { maximum of } \\
0.411 \mathrm{bm} / \mathrm{ft}^{2} \\
\left(2 \mathrm{~kg} / \mathrm{m}^{2}\right)\end{array}$ & $\begin{array}{l}\text { Maximum water } \\
\text { absorption of foam } \\
\text { prisms on water } 15 \% \\
\text { by volume } 1 \text { n } 7 \text { days }\end{array}$ & $\begin{array}{l}\text { Maximum water } \\
\text { absorpt } 1 \text { on of foam } \\
\text { prisms on water } 15 \% \\
\text { by volume in } 7 \text { days }\end{array}$ & $\begin{array}{l}\text { Maximum water } \\
\text { absorption of foam } \\
\text { cubes on water 15\% } \\
\text { by volume in } 7 \text { days; } \\
\text { and drops of methyl } \\
\text { violet solution not } \\
\text { absorbed within i h }\end{array}$ & $\begin{array}{l}\text { Maximum water } \\
\text { absorption of foam } \\
\text { cubes on water } 15 \% \\
\text { by volume in } 24 \mathrm{~h}\end{array}$ \\
\hline Fl ammabil I ty & $\begin{array}{l}\text { Flame spread } \\
\text { classification } \\
\text { maximum of } 25\end{array}$ & -- & -- & $\begin{array}{l}\text { Flame spread 1ndex, } \\
25 \text { maximum; smoke } \\
\text { 1 ndex, } 150 \text { maximum }\end{array}$ & $\begin{array}{l}\text { Flame spread classi- } \\
\text { f1cation should not } \\
\text { exceed } 75\end{array}$ & $\begin{array}{l}\text { Flame spread classi- } \\
\mathrm{f} 1 \text { cat } 1 \text { on maximum of } \\
25 \text {; interior face of } \\
\text { wall has } 1 / 2 \text { in. } \\
(13 \mathrm{~mm}) \text { gypsum board } \\
\text { or } 15 \mathrm{~min} \text { f } 1 \mathrm{n} 1 \mathrm{sh} \\
\text { rat } 1 \mathrm{ng}\end{array}$ & $\begin{array}{l}\text { Must at least cor- } \\
\text { respond with con- } \\
\text { struction material } \\
\text { classif lcation B2 } \\
\text { (normally } 1 \text { gnitable) } \\
\text { according to DIN } \\
4102 \text { Part } 1\end{array}$ \\
\hline $\begin{array}{l}\text { Consistency } \\
\text { Characteristics }\end{array}$ & - & $\begin{array}{l}\text { Must have a homogen- } \\
\text { eous and } f \text { ine } \\
\text { unif orm cell struc- } \\
\text { ture; free of flaws; } \\
\text { photograph1c stan- } \\
\text { dards are given for } \\
\text { comparison }\end{array}$ & $\begin{array}{l}\text { Essent1ally homogen- } \\
\text { eous }\end{array}$ & -- & -- & -- & $\begin{array}{l}\text { Uniform, cohesive } \\
\text { structure }\end{array}$ \\
\hline $\begin{array}{l}\text { Heat Resistance } \\
\text { (Thermal Stabl 11ty) }\end{array}$ & - & $\begin{array}{l}\text { No change in cell } \\
\text { otructure when } \\
\text { heated to } 158^{\circ} \mathrm{F} \\
\left(70^{\circ} \mathrm{C}\right) \text {, no decompo- } \\
\text { 81t10n below } 266^{\circ} \mathrm{F} \\
\left(130^{\circ} \mathrm{C}\right)\end{array}$ & -- & - & - & $\begin{array}{l}\text { Adequate clearance } \\
\text { between foam and } \\
\text { heat sources should } \\
\text { be provided }\end{array}$ & $\begin{array}{l}\text { No discoloration or } \\
\text { melting of pulver- } \\
\text { 1zed foam of at } \\
\text { least } 392^{\circ} \mathrm{F}\left(200^{\circ} \mathrm{C}\right)\end{array}$ \\
\hline $\begin{array}{l}\text { Resistance of a } \\
\text { Foamed Wall to } \\
\text { Water Penetration }\end{array}$ & -- & $\begin{array}{l}\text { No evidence of } \\
\text { moisture penetration } \\
\text { on the } 1 \text { nside of a } \\
\text { masonry wall }\end{array}$ & - & -- & - & - & -- \\
\hline $\begin{array}{l}\text { Temperature and } \\
\text { Humldity Stability }\end{array}$ & - & - & - & $\begin{array}{l}\text { Maximum } 4 \% \text { linear } \\
\text { shrinkage af ter dry } \\
\text { foam exposed to } \\
100^{\circ} \mathrm{F}\left(38^{\circ} \mathrm{C}\right) \text { and } \\
75 \% \text { RH for } 28 \text { days }\end{array}$ & - & $\begin{array}{l}\text { No test included: } \\
\text { should not be } \\
\text { applled In areas } \\
\text { which experience } \\
\text { prolonged perlods of } \\
\text { high temperature and } \\
\text { humidity }\end{array}$ & $\begin{array}{l}\text { Maximum } 4 \% \text { linear } \\
\text { shrinkage af ter dry } \\
\text { foam exposed to } \\
212^{\circ} \mathrm{F}\left(100^{\circ} \mathrm{C} \text { ) for }\right. \\
7 \text { days; no test } \\
\text { under humid condi- } \\
\text { tions }\end{array}$ \\
\hline Ash Content & -- & -- & - & -- & - & $\begin{array}{l}\text { Maximum of } 2 \pi \text { of } \\
\text { original volume of } \\
\text { foam }\end{array}$ & - \\
\hline $\begin{array}{l}\text { Dimensional cold } \\
\text { Stabllity }\end{array}$ & - & -- & - & -- & - & -- & $\begin{array}{l}\text { Maximum } 2 \% \text { dimen- } \\
\text { sional change after } \\
\text { otorage at }-22^{\circ} \mathrm{F} \\
\left(-30^{\circ} \mathrm{C}\right) \text { for } 24 \mathrm{~h}\end{array}$ \\
\hline
\end{tabular}

af Applies exclusively to exterior walls of otone-like material.

ef Amendment No. I (December 1977). 
German standard [16] will require that the installed insulation be separated from the living areas by construction panels which have a sufficient resistance against the diffusion of formaldehyde vapor. Also, in West Germany and the Netherlands, procedures have been set up to conduct limited post-installation testing of installed foams and to check whether they meet the requirements of the standards.

\subsection{ADEQUACY OF STANDARDS FOR PREDICTING FORMALDEHYDE RELEASE}

As stated in section 1 , the key issue with the use of urea-formaldehyde foam insulation for retrofitting residences in the United States has been the long-term release of formaldehyde. The literature contains reports whereby existing standards for urea-formaldehyde foam insulation have been reviewed and analyzed regarding long-term release of formaldehyde. The reviews were conducted by DOE [22], CPSC [23], Long and Schutte [24], and the Canadian Hazardous Product Board of Review [9]. In all cases, it was concluded in the reports that provisions in the standards do not adequately control the potential release of formaldehyde gas from the insulation. As is evident from table 1 , the listed standards do not contain requirements pertaining to the release of formaldehyde from foams either when initially prepared or at a later point in time. Requirements are included in some standards which deal with the free-formaldehyde content of resin and the formaldehyde concentration of foam specimens shortly after preparation. Relationships between these requirements and long-term offgassing of foam have not been established. Furthermore, it has been reported that no direct relationship exists between free formaldehyde content of the resin and the amount of formaldehyde released in service over the long term [25].

At the present time, there is no reliable method to predict the formaldehyde levels that will be produced in the home by urea-formaldehyde foam based upon a laboratory sample of the product [23]. It has been shown that urea-formaldehyde foam insulations produced according to manufacturers' specifications release formaldehyde gas over long periods of time [9]. The release will occur at normally encountered ambient temperature and relative humidity conditions and may increase as temperature and humidity conditions are raised.

\subsection{USE OF UREA-FORMALDEHYDE FOAM INSULATION IN OTHER COUNTRIES}

Information about the use of urea-formaldehyde foam insulation in other countries was obtained from building research organizations or other government related agencies. Since a review of the potential health effects associated with foam was beyond the scope of the study, requests for information were not asked from health agencies in the countries contacted. The information was requested by letter from eighteen countries and a summary of the responses which were generally received by letter are presented. Caution should be used when considering the European experience in relation to that in the United States because in many cases differences may exist regarding foam technology, application techniques, and use. 
About 10,000 homes have had urea-formaldehyde foam insulation installed. It has been used in walls and ceilings, with ceilings most favored by the industry. Some formaldehyde gas emission problems were reported, which are estimated to be less than 0.5 percent of the homes insulated with the foam. The formaldehyde emission is considered to be associated with ceiling applications.

Belgium

Up until 1982, the injection of urea-formaldehyde foam insulation was generally used for retrofitting masonry cavity walls of dwellings. Following negative reactions from abroad, particularly from the United States and Canada, the injection of the foam is no longer the most widely used technique. In general, urea-formaldehyde foam insulation has caused no specific problems, except those which occur with other insulation products (e.g., humidity). The use of the foam in filling cavity walls must satisfy a number of requirements.

Canada

Denmark

Urea-formaldehyde foam insulation had been installed in an estimated 80,000 to 120,000 homes, mostly wood frame, before it was banned in 1980. Other applications included commercial, institutional, and high rise buildings. In December 1980 , the Canadian Government announced an assistance program for homeowners to cover testing, technical advice, and foam removal or other remedial action.

From 1976 to July 1981, 6500-9000 buildings were insulated with urea-formaldehyde foam insulation. During July 1981 to July 1982, approximately 800 buildings were insulated with foam. After July 1982, the use of the foam declined. There were several cases where it was necessary to remove the foam and others where remedial actions were attempted. Regulations are in preparation that will require the formaldehyde concentration in the room air not to exceed $0.15 \mathrm{mg} / \mathrm{m}^{3}(0.13 \mathrm{ppm})$.

Finland

Urea-formaldehyde foam insulation was used very much during 1960-1970, but later its use decreased. The foam was installed in wood-frame cavity walls of houses which had saw dust or cutter chips as insulation. It was found that the foam did not mix with the old insulation and that there was little improvement of thermal conductivity. Few problems have been reported with the use of the foam. Those which occurred, for example, the peeling of paint on exterior wall surfaces, were attributed to the water in the foam. Formaldehyde emission problems were described as not being usual. Where they occurred, it was indicated that the outer wall of the construction was tight. 
France

Great Britain

The Netherlands

New Zealand

Norway
Foam insulation had little use in France before 1974. Since then about 150,000 applications have been realized. Application is controlled through the Avis Technique certificates which allow for installation only in cavity walls. The walls must provide protection against mechanical shock damage to the foam, moisture accumulation in the foam, and exposure to high temperatures. Because of formaldehyde emissions, considerations of regulations for use are being undertaken, but are not established at this time.

The use of urea-formaldehyde foam insulation started in the early 1960s, reached its peak in the early 1970s and has declined rapidly over the last few years. The decline in use is attributed to reports of problems in the United States and the use of alternative materials entering the market. It is estimated that approximately one million buildings have been insulated with foam. In 1970, the use of the foam was restricted to cavity masonry walls in buildings less than 10 meters high and with limited exposure to driving rain. In 1975 , it was required that the foam producers have an Agrément Certificate and that the installer be approved by the Agrément Board. The problems, as long as the installation has been restricted to the Agrément Certificate or the British Standard, have been minimal. The British Standard and Code of Practice were published in 1978 [15, 21].

Urea-formaldehyde foam insulation has been used to a fairly large extent in masonry wall cavities from 1974 to about 1980. It is not used in ceilings. Because of adverse publicity on formaldehyde emission from particle board, coupled with negative reactions about foam use in the United States and Canada, the installation of urea-formaldehyde foam dropped dramatically. The number of complaints reported was very low.

Urea-formaldehyde foam insulation has been used since the late 1970s. Approximately 1000 homes have been insulated with foam. No major problems have been reported. A code of practice to minimize poor installation was considered necessary.

There has been little use of urea-formaldehyde foam insulation in Norway. Around 1970, some houses which were built during 1945 to 1960 were insulated with foam. It was considered ineffective in that it did not fill the cavity and in some walls a few years after installation it had collapsed into a dust-like powder. 
Sweden

West Germany
Urea-formaldehyde foam insulation is used only for retrofitting existing buildings, mainly houses. The foam is used in cavity walls, attic floors, and other voids in wood frame houses. The volume presently installed is estimated to be $1200 \mathrm{~m}^{3} /$ year. The installation is often made by very small firms, without sufficient technical competence and responsibility, which has caused some problems. The performance of the foam insulation has in general been good.

The main use of urea-formaldehyde foam insulation is in cavity walls of old houses and in some cases new buildings. Normally the type of construction is brick or concrete masonry cavity walls. The foam thickness is generally 60-80 mm. Few problems have been reported with the use of the foam. Since 1981, government standards require that the foam be separated from the living areas by construction panels which have sufficient resistance against the diffusion of formaldehyde. 


\section{FACTORS AFFECTING THE PERFORMANCE OF UREA-FORMALDEHYDE FOAM INSULATION}

During the previous NBS review of urea-formaldehyde foam insulations, a 1ist of twenty-five factors affecting the performance of these materials as thermal insulations was compiled [5]. These factors were discussed based on literature publications, test reports, available standards, and limited preliminary NBS test results. In many cases, the discussions of some factors were limited because of a lack of published information on those aspects of performance.

An identical approach has been taken in this present review of the properties and performance of urea-formaldehyde foams. Since the publication of the NBS review in 1977 [5], many reports and tests results concerning the properties and performance of foams have been published. To review these reports and test results a list of factors affecting the performance of urea-formaldehyde foam is again given. Discussions of each of these factors are presented in the sections of the report which follow.

The factors which were considered in this study and discussed in this report are:

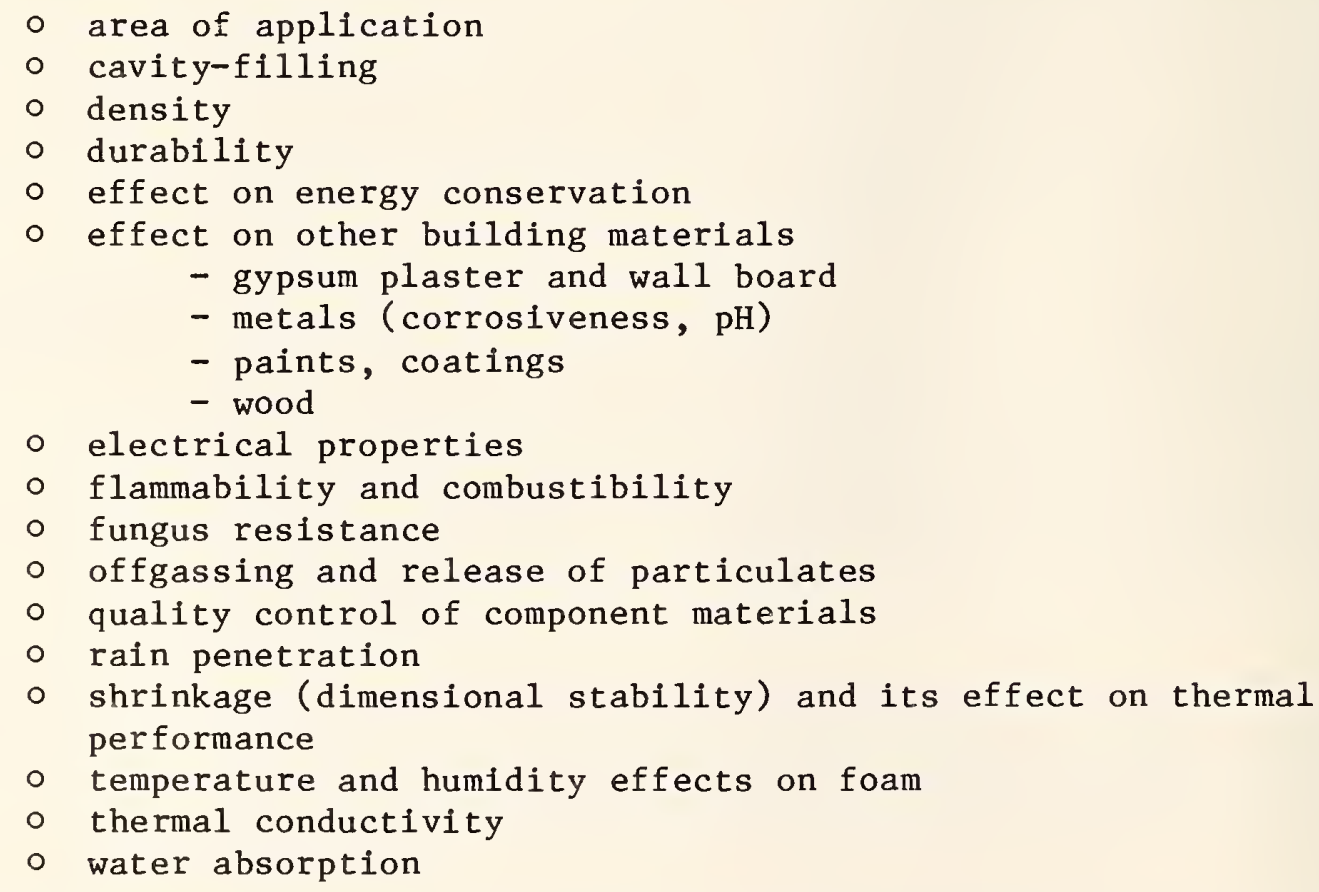

Other performance factors were identified in the 1977 review [5], but are not discussed in this report. Examples include consistency, photodegradation, specific heat, and water vapor transmission. Little additional information has been published with regard to these factors. In general, the factors affecting performance discussed in this report are those for which new information has become available through recent laboratory and field research. 


\subsection{AREAS OF APPLICATION}

The normal area of application for urea-formaldehyde foam insulation in North America was the cavities for exterior wood-framed walls of residences, although the insulation has been used for interior partition walls, masonry walls, below grade applications, ceilings and attics [26]. In some cases, standards have indicated restrictions as to areas of residences where the foam should not be installed. These application restrictions are not consistent among all documents. For example, the DOE standard [18] and the Canadian standard [13] limited use to exterior sidewall applications. The HUD bulletin [19] allowed use in enclosed building cavities such as walls, partitions, and floors, but disallowed use in attics and ceilings. The ASTM standard [17] indicates that the foam is intended for application in vertical closed cavities without making distinction between exterior sidewalls and interior partition walls.

The restrictions given in standards concerning areas of foam application were based on considerations of formaldehyde release from foams into residences, and the deleterious effects of exposure of foam to moisture and combined elevated temperature and humidity conditions. For example, if the insulation is installed in interior partition walls, formaldehyde released from the foam can, in all likelihood, only be given off to the interior of the residence, unless convection transports it upwards into the attic space. Additionally, since foams can be degraded by exposure to elevated moisture and temperature conditions [27], installation in areas which might experience those conditions such as above ceilings and in attics should be avoided. In one case, NBS research personnel have had the opportunity to observe a urea-formaldehyde based foam insulation installed in the attic of a residence located near Norfolk, Virginia [28]. The foam was extensively cracked, although no cracks were seen to have penetrated directly through the foam to the ceiling since the insulation was applied in two layers. The top surface (about $0.5 \mathrm{in}$. or $13 \mathrm{~mm}$ ) of the foam was yellow, friable, and powdery. Scanning electron microscopy (SEM) analysis of the foam near the top surface indicated cellular degradation which typically occurs from elevated temperature and humidity exposure [27].

Some European documents such as the British code of practice [21] and the Netherlands standard [14] limit use of urea-formaldehyde foam insulations to double-leaf masonry cavity walls. Although some wood-frame residential construction exists in these European countries, insulating wood-frame cavities with urea-formaldehyde foam is not allowed. The British Building Research Establishment (BRE) has recommended that cavities between timber framing and brick external leaves not be filled with foam [29]. The Australian Experimental Building Station (EBS) also recently recommended that foam use should be restricted to double-leaf masonry cavity walls [30].

The British Building Research Establishment (BRE) has provided an explanation for the European limitation to use in double-leaf masonry cavity walls [31]. The limitations are in part based on the capability of these types of cavity walls, which are plastered on the inner leaf, to vent formaldehyde released from foam to the exterior of the residence. In an early BRE report, it was indicated that with this type of wall construction, formaldehyde vapors from foam rarely enter the residence [31]. However, in a later BRE report, it was stated that 
a risk always exists [29]. According to the BRE, it is considered that a greater risk of formaldehyde entry into the residence will occur when the inner facing of the cavity is vapor permeable (e.g., plasterboard), particularly if the outer facing is impermeable [31]. Data supporting these statements on formaldehyde release into residences, as influenced by wall construction, were not given in these BRE reports [29,31]. More recently in 1984, a third BRE report indicated that, in a limited number of cases, after insulation of the masonry cavity wall with foam, formaldehyde can enter the residence [32]. It was stated that the formaldehyde emission is greatest during the first few days after installation, but can continue for some months or years depending upon the formulation of the foam. The pathway for vapor entry into the residence from the cavity wall was considered to be a discontinuity in the inner leaf of the wall [32].

The U.S. Franklin Institute has reported that, when interior and exterior surfaces are in thermal, barometric, and moisture equilibrium, transmission rates of formaldehyde through an interior painted gypsum wall board is at least ten times as great as that through a conventional exterior wall, even if the latter surface is vented [33]. Consistent with the BRE reports, the Technical Research Center of Finland has also indicated that it is best not to install foam in cavities having porous wallboard, since formaldehyde may permeate into the living space [34]. Also the French Centre Scientifique et Technique du Batiment (CSTB) has indicated that problems in France due to formaldehyde penetration into the living space have occurred in light-frame constructions which have wallboard or similar facing [35]. These reports primarily considered diffusion and not air leakage. A recent report from England has indicated that formaldehyde vapors increase in the residence immediately after foam application [36].

The fact that some European countries restrict the use of urea-formaldehyde foam insulations to masonry cavity walls (thereby not allowing use in wood-frame constructions) raises a question as to the suitability of using these insulations in wood-frame residences in the United States. Hawthorne and Gammage [37] have reported that foam-insulated test panels, constructed with an interior facing of gypsum board and exterior facing of cellulosic sheathing and aluminum siding to simulate the walls of a house, showed significant potential for formaldehyde emission even about 16 months after foam installation. These tests were conducted under both static and dynamic air conditions with air flow selected to simulate a typical air exchange found in residences.

The results of Hawthorne and Gammage [37] are consistent with the British BRE concerns [29, 31] that formaldehyde from foam can penetrate through permeable wall facings. During this present review, no other reports were found concerning formaldehyde transmission through walls as related to the type of wall construction. Controlled studies to assess the relative potential of formaldehyde to be transmitted from the foam through interior and exterior facings of wall constructions as influenced by the relative permeances of the facings and the tightness of the constructions have not been reported. 


\subsection{CAVITY FILLING}

The primary application of urea-formaldehyde foam insulation has been to retrofit sidewalls of existing residences. As such, the foam is pumped under pressure in a semi-fluid state into inaccessible closed cavities where it sets or hardens into a rigid self-supporting material. The extent to which the closed cavities are filled is difficult, if not impossible, to assess visually, although thermography methods may be used. The extent of cavity filling is of prime importance, since the thermal efficiency of an incompletely filled cavity is significantly reduced in comparison to the totally insulated cavity [38]. When properly applied (for example, the set time of the foam is not too short in relation to the volume of the cavity), the foam in its semi-fluid state under pressure can flow throughout the cavity to achieve a complete fill. In some instances because of ease of flow, areas of residences such as eaves and soffits, floors, and ceilings, which were not intended to be insulated, have been partially filled with foam [39].

Two major parameters influence the filling of wall cavities: (1) the setting time of the foam (i.e., the time after application during which the foam hardens to become self-supporting), and (2) the application technique including the quality of workmanship during application. In the first case, if the setting time is too short, then the foam may harden before the cavity is filled. Or, if the setting time is too long, then the semi-liquid foam may collapse, leaving an incompletely filled cavity. Standards and specifications have requirements concerning maximum and minimum limits of the setting time. For example, the HUD bulletin [19] indicated that the setting time should be between 20 and 60 seconds for applications in closed cavities. Examples of incompletely filled cavities attributed to improper setting time of the foam have generally not been reported in the literature. In one case of a brick and concrete block construction, rapid setting of the foam was given as the probable reason for incomplete fill of the cavity [40].

Observations of foam-insulated wall cavities opened for inspection during field studies conducted to assess the performance of retrofit insulations in-service have been made [40-43]. These observations have provided evidence that poor workmanship during application of urea-formaldehyde foam has resulted in many instances of incompletely filled cavities. In addition, Shirtliffe has indicated that in his Canadian experience, poor filling of cavities may occur almost as often as complete filling [44]. More recently, removal of foam from residences in Canada has provided other examples of cases where the insulation only partially filled the cavities [45].

Because of instances of poor workmanship including incomplete cavity fill, Weidt et al. recommended that, to minimize the possibility of poor workmanship, voluntary consensus standard practices for installation of retrofit insulations including urea-formaldehyde foam be developed [42]. Presently in the United States a standard application practice does not exist, although an interim application practice was issued and subsequently withdrawn by the U.S. Department of Energy [46]. A provisional application standard was also available in Canada in the late 1970s [20]. In the United Kingdom a code of practice for the installation of this insulation is available [21]. These documents described 
techniques and guidelines to assist applicators in the total filling of cavities. Their effectiveness in controlling the quality of application has not been reported. It is believed that the DOE document [45] was not available for a sufficient period of time to have been used extensively.

The Canadian application standard [20] was available for approximately 3 years. In spite of its use over that period of time, as mentioned, the Canadian experience with foam application has shown many cases where cavities were only partially filled [45]. This raises a question as to whether the standard was ineffective or not followed by the applicators.

In a practice related to filling uninsulated cavities with urea-formaldehyde foam, these insulations have been used to re-insulate cavities which were partially insulated with 1 to $1.5 \mathrm{in.}$ ( 25 to $38 \mathrm{~mm}$ ) thick fibrous glass batt insulation. Limited field observations have indicated that, in these applications, the batts have been compressed and that measurements of foam shrinkage have not been carried out because of the presence of the batts [42]. The extent of batt compression is influenced by the application technique used for foam installation. Sufficient data are not available in the literature to evaluate fully the effectiveness of this type of application. One possibility is that the presence of the batt may act as a "reinforcement" for the foam and reduce shrinkage.

\subsection{DENSITY}

As applied, wet urea-formaldehyde foam insulations may contain approximately 75 percent water by mass. The wet density of the foam may be measured at the job site by applicators immediately prior to installation and compared to the manufacturer's recommended wet density as one indicator that proper application techniques are being followed. As a consequence, the ASTM and DOE standards for foams have included requirements for wet density (Table 1). Wet density values given in the ASTM standard range from 2.5 to 5.5 . $1 \mathrm{bm} / \mathrm{ft}^{3}$ (40 to $88 \mathrm{~kg} / \mathrm{m}^{3}$ ). Shirtliffe has questioned whether control of the wet density of foam may be used as an indicator of the performance properties of the dry product [44].

Minimum and maximum values for the dry density of foams have also been included as requirements in standards and specifications (Table 1), with the minimum value being greater than about $0.61 \mathrm{bm} / \mathrm{ft}^{3}\left(10 \mathrm{~kg} / \mathrm{m}^{3}\right)$. The dry density of urea-formaldehyde foam insulations is not considered to be a performance property in itself, but parameters such as mechanical properties and thermal conductivity are related to density [43]. As noted in NBS Technical Note 946, a foam insulation having a density within the recommended range may perform poorly [5]. For example, it was found in one laboratory test that a foam specimen having a density of $11 \mathrm{bm} / \mathrm{ft}^{3}\left(16 \mathrm{~kg} / \mathrm{m}^{3}\right)$ underwent excessive shrinkage and yellowed upon about 2-months exposure to combined elevated temperature and humidity conditions [27]. Dry density may be used as a measure that a foam insulation has been applied according to a manufacturer's recommendations [5]. Foams with densities beyond the normally recommended range may not have been applied according to recommended practice. 
Dry densities of foam specimens removed from walls of U.S. residences during field surveys in the late 1970 s have been reported $[42,43]$. In one study [42], the average density of 25 samples was $0.71 \mathrm{bm} / \mathrm{ft}^{3}\left(11.5 \mathrm{~kg} / \mathrm{m}^{3}\right)$ with a range of values from 0.34 to $1.151 \mathrm{bm} / \mathrm{ft}^{3}\left(5.4\right.$ to $\left.18.4 \mathrm{~kg} / \mathrm{m}^{3}\right)$. Eleven of these samples had densities less than $0.71 \mathrm{bm} / \mathrm{ft}^{3}\left(11.5 \mathrm{~kg} \cdot \mathrm{m}^{3}\right)$ which is specified as the minimum in the ASTM standard [17]. In the second study [43], 12 foam samples were found to have an average density of $0.81 \mathrm{bm} / \mathrm{tt}^{3}\left(12.8 \mathrm{~kg} / \mathrm{m}^{3}\right)$ with values ranging from 0.5 to $1.051 \mathrm{bm} / \mathrm{ft}^{3}$ (8 to $\left.16.8 \mathrm{~kg} / \mathrm{m}^{3}\right)$. In this case four of the twelve samples had densities less than $0.71 \mathrm{bm} / \mathrm{ft}^{3}\left(11.5 \mathrm{~kg} / \mathrm{m}^{3}\right)$. It is noted that the foam samples investigated in these studies were installed in residences prior to 1979 and the development of the ASTM standard. The earlier recommendation for minimum density value of urea-formaldehyde foam insulation was generally $0.61 \mathrm{bm} / \mathrm{ft}^{3}\left(10 \mathrm{~kg} / \mathrm{m}^{3}\right)$ [5].

\subsection{DURABILITY}

Durability is the capability of a building product or component to maintain its serviceability over a specific period of time [47]. Durability may be determined through in-service performance or estimated through accelerated aging tests. Since urea-formaldehyde foam insulations are installed in closed cavities, it is difficult to observe their in-service performance over time. Few studies have been conducted in the laboratory to estimate their service life through accelerated aging tests. The evidence in the literature concerning durability is contradictory.

The British Building Research Establishment (BRE) reported in 1980 that urea-formaldehyde foam insulations used in the United Kingdom in masonry cavity walls should be expected to last the lifetime of the building without significant deterioration, provided that the foams are processed and installed correctly [31]. In 1980, Bowles and Shirtliffe [40] reported that on the basis of evidence at that time, properly installed foams should be stable for an adequate period of time. They did not qualify the time period. They also indicated that field investigations produced evidence that foams having up to eight years service showed no signs of significant deterioration. However, subsequent to their early investigations, additional evidence was reported by Bowles and Shirtliffe [40] that in two cases, foams in sidewalls had undergone extensive deterioration in 4 years or less. In reporting on the experiences in the Netherlands, Wulkan [48] indicated that foam specimens have remained intact in cavities after 10 years or more service. Observations from field investigations in the United States did not specifically address the question of the durability of foam installed in sidewalls and pertinent measurements in this regard were not made $[42,43]$. In general, evidence was not presented in these studies which indicated that the durability of the foams inspected in the field investigations was suspect. In a limited number of cases, foams were described as having a powdery, friable, or slightly yellow surface [42]. As one further example, during this present study, a foam having 4 to 5 years age was observed as it was being removed from the walls of a residence. This foam appeared to be in good condition without signs of deterioration, although no measurements were made to support this observation. 
In contrast to the reports and observations noted above that the durability of urea-formaldehyde foam insulations may be adequate, other limited evidence was found that the durability of some foams may be suspect. Chown et a1. [49] have reported that foam deteriorates continuously at a moderate to rapid rate so it has a short life compared with other building materials. During this present review, two examples were seen of foams which were about 7-10 years old and which were extremely friable, powdery, and had little strength. In the worse case, the foam collapsed to a powder upon slight finger-tip pressure. In both cases, air movement such as that produced by blowing across the foam surface resulted in release of many fine particles. Factors contributing to the conditions of these foams have not been investigated. As another example of poor durability, it was found that when cavity walls of a Canadian school outside of Ottawa were opened to remove foam, the insulation was not there but a powder was found on the bottoms of the cavities [50]. The powder was attributed to the disintegration and collapse of the original foam which had reportedly been installed 27 years before the opening of the cavity walls.

Although the documented number of cases of foams having suspect durability may be sma11, the limited observations raise questions concerning current practices for selecting and evaluating these insulations. In particular, the ASTM standard [17] does not have a requirement addressing the long-term performance of foams. A methodology does not exist to assist the evaluation of foam durability. One of the critical parameters affecting the long-term performance of urea-formaldehyde foam insulations is their resistance to combined elevated temperature and humidity conditions. This parameter is discussed in section 3.14.

\subsection{EFFECT ON ENERGY CONSERVATION}

As a thermal insulation, it would be expected that installation of ureaformaldehyde foam in sidewalls of residences would result in decreased energy consumption. The thermal conductivity values of urea-formaldehyde foam specimens, removed from the walls of residences in one field investigation, were on the average found to be slightly lower than values determined for cellulose or fibrous glass specimens [42]. The U.S. Department of Energy has indicated that in general the 1ikely savings of energy attributed to retrofitting a home with urea-formaldehyde foam would be 15 to 20 percent [51]. These values could be less if the retrofit was not adequately completed. The exact percentage of fuel savings achieved cannot be anticipated a priori because of the many factors involved including: the effect of foam shrinkage, the type of building construction, environmental conditions to which the house is subjected, durability of the foam, living habits of the occupants, other retrofit measures undertaken along with insulating, and the quality of workmanship during insulation application. In this regard, the French Centre Scientifique et Technique du Batiment (CSTB) reported that it is difficult to describe precisely the reduction in heat losses achieved by insulation with foam [52]. The CSTB report also stated that it is undeniable that installation of the foam will result in an increase in the overall thermal resistance of the building walls. It was indicated that the effect of foam application would be perceptible both from the point of view of fuel consumption and also in the comfort of the building occupants [52]. 
Few quantitative reports are available which describe the effect of the foam insulation on energy conservation. Two reports were cited previously by NBS [5]. In one study, the amount of fuel saved was about 30 percent, and in the other 23 percent. Two other reports have become available from the Netherlands. One report described an average savings of about 20 percent [53], while according to the second report [54], the savings ranged from 17 to 28 percent with an average savings of about 22 percent.

Since urea-formaldehyde foam insulations may shrink continuously over time periods up to two years after installation [55], the question may be asked whether the energy-conservation effectiveness of foam decreases with time. Reports addressing this question were not found during this survey. The effect of shrinkage on thermal performance of foam-insulated walls is discussed in section 3.13 .2 .

\subsection{EFFECT ON OTHER BUILDING MATERIALS}

The application of wet urea-formaldehyde foam insulation which has an acid catalyst into cavity walls of residences may conceivably adversely affect the performance of other building materials in contact with the foam. As an estimate, a typical foam installed in a wood-frame wall cavity having nominal dimensions of $8 \mathrm{ft} \times 16 \mathrm{in.} \times 3.5 \mathrm{in.}(2.4 \mathrm{~m} \mathrm{x} 400 \mathrm{~mm} \times 88 \mathrm{~mm}$ ) may contain up to $111 \mathrm{bm}(5.1 \mathrm{~kg})$ of water. This water and water soluble constituents from the foam may be absorbed by building materials such as wallboard and wooden framing and siding, and the water and acid catalyst may lead to corrosion of metals. In the mid-1970s, data were lacking in the literature to assess the effect of foam on other building materials [5]. Since then, more has been learned through field observations and laboratory testing. Materials which may be adversely affected by the installation of foam include gypsum plaster and wallboard, masonry materials and mortar, metals, paints or coatings, and wood.

\subsubsection{Gypsum Plaster and Wa11board}

Reports describing field surveys conducted on urea-formaldehyde foam insulation in-service have not specifically discussed the effect of the foam on gypsum plaster and wallboard [41, 42]. In general the observations reported were favorable. Statements in these reports that the foam installation was in general not found to have adversely affected the wall cavities may be interpreted to mean that adverse effects on gypsum plaster and wallboard were not observed.

A major concern with the installation of wet foam has been that the water in it will rapidly drain downwards and accumulate at the bottom of the cavity. This could result in, among other adverse consequences, damage to gypsum plaster and wallboard at the bottom of the cavity. To minimize risk of such an occurrence, a water drainage test has been included in the ASTM and other standards (table 1). This test was designed for quality control in worst-case situations where water would drain too rapidly from foams to the bottom of the cavity. In the ASTM standard, a wooden cavity, constructed such that water would readily flow from it, is filled with foam and allowed to stand for 24 hours. During 
this time water from the foam should not be observed to have flowed from the cavity. Reports describing the results of this test procedure and its effectiveness for indicating foams which have a potential for accumulating water at the bottom of cavities have not been given in the literature. The Canadian field experience gained in opening cavity walls for foam removal has indicated cases where drainage of water to the bottom of cavities has occurred [45]. However, the reliability of the test method has been questioned at an ASTM task group meeting because of the use of a wooden cavity in the procedure [56]. It was considered that the moisture content of the wood of the test cavity and its ability to retain water would influence the results of the test.

\subsubsection{Masonry Materials and Mortar}

The effect of urea-formaldehyde foam insulation on masonry materials and mortar has received little attention in the literature. In England over 1 million residences have been insulated with foam and its use has been considered satisfactory [32]. Shirtliffe [11] has indicated that the acids and water in foam can sometimes react with non-metals such as lime and portland cement mortar, brick, concrete, and marble. Although few problems have been reported, he further indicated that sufficient reason for concern existed regarding the adverse effect of foam on masonry materials that the National Research Council, Canada, was initiating an extensive survey of masonry and commercial buildings. The results of the survey have not been reported. One case was described where accelerated deterioration of concrete blocks in contact with foam for 2 years was noted [44]. In another construction, stone walls having lime mortar in contact with urea-formaldehyde foam collapsed, while stone walls in sections of the construction where foam was not used did not collapse [44]. In these two cases, the report did not present a complete discussion of the factors which may have contributed to the deterioration and failure of the masonry walls. It is noted that the ASTM Standard (table 1) for urea-formaldehyde foam insulation does not have a test requirement concerning potential adverse effects of foam on masonry materials and mortar.

The National Research Council (NRC), Canada, has also questioned the practice of using foam insulation in cavities directly behind brick external wall facings [44]. It was indicated that the installation of the foam in those locations may prevent the circulation of air necessary for wetted bricks to dry and to prevent failure by freeze-thaw action. Such failures have reportedly been found with brick walls insulated with urea-formaldehyde foam in Canada [44]

\subsubsection{Metals}

When injected into a wall cavity, the potential exists that urea-formaldehyde foam insulation may cause corrosion of metal objects such as pipes, ties, electrical junction boxes, electrical connections between dissimilar metals, or wiring due to the water and acid catalyst in the foam. In the 1977 NBS report [5], it was stated that the information available at the time concerning corrosiveness was contradictory. Some reports described foams as non-corrosive, while others indicated that the foams could be corrosive in some cases. However, little information concerning corrosiveness, based on in-service performance, 
was available at that time. Recent additional information has indicated that in some cases, corrosion of metal wall objects has been attributed to the presence of the foam. In other cases, metal objects without corrosion have been found in walls insulated with foam.

In their survey of homes containing retrofit insulations, Weidt et a1. [42] reported that the few metal electrical components observed in walls showed little, if any, signs of corrosion. However, these authors acknowledged that their observations were limited and advised further information was needed on this important question. As another example, during this present study, galvanized electrical junction boxes were observed in some apartments where foam was being removed from the walls. Many of these junction boxes, which were in the walls with the foam insulation for 4-5 years, were seen to be in good condition with little evidence of corrosion.

In contrast to these observations, Shirtliffe [11, 44] has reported examples where serious corrosion has occurred and was attributed to the presence of the foam. The examples included electrical service boxes, ground wires attached to boxes, terminals of receptacles, galvanized brick ties, and steel studs in walls. In the case of one high rise building having a brick facing, it was reported that 25 percent of the ties corroded to failure in less than 5 years.

Because of the concerns over the potential corrosiveness of some foam insulations, laboratory tests have been conducted to support the development of test methods for incorporation in standards. The Department of Public Works of Canada conducted accelerated tests on steel and galvanized steel specimens in contact with water-presaturated foam and dry foam at $120^{\circ} \mathrm{F}\left(49^{\circ} \mathrm{C}\right)$ and 96 percent relative humidity [57]. The results indicated that the foams, were corrosive to the specimens under the test conditions, and that the corrosiveness could vary markedly with foam formulation. It was also shown in this study that the surfaces of foam samples could be more acidic than the interior of the samples. Weil et a1. [58] conducted corrosion tests on both wet foam (as foamed-in-place) under ambient conditions, and on dry foam at $104^{\circ} \mathrm{F}\left(40^{\circ} \mathrm{C}\right)$ and at saturated humidity conditions. The tests were run on steel, galvanized steel, copper, and aluminum. Corrosion rates were variable depending upon the test conditions and metal specimens. For example, in the wet foam test, steel coupons exhibited initially high corrosion rates while the foam remained wet, but lower rates occurred as this foam dried. In the dry foam test, galvanized steel coupons had in several, cases corrosion rates which exceeded the failure values specified in the test procedure. For both wet and dry tests, corrosion rates of copper and aluminum were low. Based on the test results, Weil et al. [58] recommended that the corrosiveness of foam insulations be evaluated using both a wet foam and a dry foam test procedure.

Clifton et al. [59] investigated the corrosiveness of one urea-formaldehyde foam insulation sample and one cellulosic insulation. The composition of the foam was not known, but the sample was described as a commercial material available from a major distributor. The cellulosic insulation had on a weight basis 2 percent ammonium sulfate and 1.5 percent aluminum sulfate. Electrical boxes were filled with these insulations and subjected to constant relative humidities of 44, 75, and 96 percent at ambient temperature. The results indicated that the 
urea-formaldehyde foam tested was mildly corrosive, but considerably less than the cellulosic specimen tested. Based on the results, these authors expressed the concern that moist thermal insulations could conceivably accelerate the corrosion of metallic pipes and other metallic building materials, in addition to corrosion of electrical devices.

Because of the serious concerns which have arisen from field observations and laboratory tests regarding the potential corrosiveness of some urea-formaldehyde foams, most standards for the insulations have incorporated corrosion test requirements (table 1). In particular, the ASTM standard [17] incorporates two test procedures: one using freshly-prepared (wet) foam specimens, and the other using dry (cured) foam specimens. In both procedures, carbon steel, galvanized iron, copper, and aluminum metal coupons may not have corrosion rates exceeding specific limits, when exposed with foam samples under the conditions of the test. Data have not been reported in the United States as to the performance of typical commercially-available foam insulations in these ASTM tests. Moreover, the relationship of the performance of foam specimens in these tests and in-service performance has not been established. It is noted that the ASTM corrosion test procedure for dry foam specimens is essentially identical to that incorporated in the Canadian standard. It is from Canada that most reports have appeared regarding the corrosion of metals exposed to foam in service [11, 44]. This fact raises the question as to whether or not the test method in the Canadian standard (and thus ASTM standard) was adequate for distinguishing between potentially corrosive foams and those which may be non-corrosive.

Another point should be mentioned regarding the ASTM corrosion requirements. In the freshly-prepared (wet) foam test procedure, corrosion rates are determined for the metal coupons tested for 28 and 56 days exposure. In the procedure, corrosion rates are significantly greater over the initial few days of testing when the foam contains the water present during installation [58]. However, in calculating the final corrosion rate, the rate for 28 days is subtracted from that for 56 days. Thus, it may be possible that all foams, no matter what their potential wet corrosiveness, may pass this ASTM test requirement, since the final calculated corrosion rates do not consider the rates for the time when the foam is wet and perhaps most corrosive.

Reasons why the corrosiveness of foams may vary among different products or samples have not been investigated through controlled laboratory studies. Many factors may be hypothesized to influence the potential corrosiveness including: the foam formulation (e.g., type and amount of acid catalyst, presence of latent bases to neutralize acid catalyst), variability in composition due to non-uniform mixing of components during application, length of time that the foam remains wet after application, the tendency of the foam to become moist again after drying, the rate of drying, and the $\mathrm{pH}$ of the surface of the foam. As the freshly installed foam dries, the acid catalyst may migrate to the surface along with the water present during application, particularly if the rate of drying is rapid $[40,57]$. The $\mathrm{pH}$ of the surface of the foam may, then, in many cases, be lower than at the core of the foam. A result of the acid migration may be that corrosion of metal objects in walls insulated with foam may occur and be accelerated at locations on the metal which would not 
experience such corrosion in the absence of foam. Weidt et al. [42] investigated the acid migration phenomenon as part of their field survey by determining the $\mathrm{pH}$ of the exterior and interior surfaces of foam specimens, as well as that at the middle. In this study, crushed foam specimens were digested for 5 minutes in boiling water and the $\mathrm{pH}$ of the resulting solution was measured. For twentyfive specimens the interior surfaces had an average $\mathrm{pH}$ value 0.8 units less than that of the middle, which was approximately the same as that of the exterior surfaces. Only eight of the specimens showed the middle sections to have $\mathrm{pH}$ values greater than those of both surfaces. It should be noted that the measurement of the $\mathrm{pH}$ of foam has never been standardized and errors in measurement have not been defined. Comparisons between measurements must be made with caution since the procedures in different cases may vary.

\subsubsection{Paints and Coatings}

Although concerns have been expressed [5] that the water present in foam during application may increase the risk of blistering and peeling of paints or coatings on wall surfaces, this factor affecting performance has received little attention in the literature. As the foam dries, the water will normally migrate towards the exterior of the house in the winter and towards the interior in the summer. In either case, if the wall construction is tight and the paint on the surface is a good vapor retarder, the paint may possibly blister provided that means of venting is not available.

Weidt et al. [42] observed no problems with paints or coatings on exterior walls of cavities insulated with foam whereby the problems could be directly attributable to the foam installation. In contrast, Burch and Hunt [55] observed blistering of the exterior paint on a residence at those sections of a wall which was insulated with foam. The Technical Research Center of Finland also has indicated that in a few houses exterior paint has failed due to the migration of moisture from the foam into the outer surface [60]. To avoid paint blistering as well as other problems, foam insulation should not be applied to wall cavities from which the water cannot be adequately vented [34,61].

\section{6 .5 Wood}

Building performance technologists have long expressed concerns that the water present in foam during application could result in rotting of wood members of cavities, if the water could not dry from the cavity [34, 61, 62]. In 1976, before the use of urea-formaldehyde foam insulation began to increase rapidly in the United States, the Technical Research Center of Finland recommended that the wet foam should not be applied in cavities in which adequate drying would not occur [34,61]. In one study in the Washington, D.C. area, it was shown that the water in the foam migrated into wooden members after wintertime installation and dried the following spring [55]. It was also shown that the foam retained some water over two months after the winter-time installation and dried the following summer [55]. No means of providing venting of the walls of the house were attempted.

In general, the moisture content of wood must remain over 20 percent for more than 2 weeks to establish wood rot [26]. Information available in the literature 
indicates that, at least in some cases, a risk is present that adequate drying of the installed wet foam may not occur as intended. In the majority of cases for which data are available, adequate drying appears to occur. Once adequate drying occurs, the moisture content of the wall should not in general be expected to increase to high levels due to the presence of the foam in comparison to the presence of the other retrofit insulations.

Field surveys in the United States have not found moisture problems in wood-frame wall cavities which were attributed to installation of the foam [41-43]. For example, in examining insulated and uninsulated walls of 93 residences in the Portland, Oregon region, Tsongas et al. [41] found that moisture contents of wooden members were never greater than 20 percent as long as water entry problems such as leaks in the wall or roof were absent. In this study 43 residences contained urea-formaldehyde foam insulation which had been in place a minimum of three years. In contrast, some observations in Canada have shown some foam-insulated houses to have moisture contents considered to be too high and moisture-induced damage to wooden members of walls has occurred $[11,44]$.

The most extensive data concerning moisture in wooden members of cavities insulated with urea-formaldehyde foam insulation has been provided by the UFFI Centre (Urea-Formaldehyde Foam Insulation Information and Coordination Centre), Canada [63]. As part of the Canadian National Program on foam insulation, the moisture contents of wooden members of more than 50,000 cavities in about 12,000 residences, which in general had a number of years age, were measured using a resistance probe method. The residences were located across Canada and the foam had in general been installed at least a year before the moisture measurements were made. About 3.3 percent of the residences had one or more wall cávities with moisture contents of wooden members of greater than 20 percent.

In another Canadian study, predictions were made as to the number of moisture problems which may occur in future years in Canadian-government financed housing [64]. The predictions were based on a field survey of existing housing and listed six classifications of moisture problems including moisture in wooden members of wall cavities. From the results it was estimated that about 1.4 to 1.6 percent of future housing (without foam) might have moisture problems depending upon the number of housing starts.

These predicted percentages ( 1.4 to 1.6 percent) of total moisture problems in new future housing were less than the percentage (about 3.3 percent) of moisture problems found in wall cavities of the older homes insulated with foam. It is difficult to make a direct comparison between these two Canadian studies, not knowing whether a statistically significant difference in the results of the two exists.

Guidelines regarding foam application into wall cavities where satisfactory drying will occur have not heen developed in the United States. In this country, foam has been applied in both new and existing construction. In Canada, government agencies had in the past discouraged its use in new construction [11]. It was reasoned that the wood in new construction had not fully dried 
and already contained so much water that there was little capacity to absorb additional water from fresh foam without risk of problems.

\subsection{ELECTRICAL PROPERTIES}

Urea-formaldehyde foam insulation is applied wet in cavity-walls containing electrical system components such as wiring and junction boxes. Thus, a potential for shock hazards may exist to installers and others who may come in contact with the freshly-installed wet foam, which may conduct electricity. Although this property has received little attention in the literature, the ASTM and other standards (table 1 ) contain a requirement that the minimum electrical resistivity of freshly installed foam not be less than $5 \mathrm{k} s \cdot \mathrm{cm}$ to minimize risk of shock hazards. The HUD bulletin [19] recommended that power lines in excess of 200 volts in cavities in which foams are applied should be shut off until the foam dried or the cavities were sealed. In cases where the applicator might be standing on wet ground or might not be electrically insulated from wet ground, the HUD bulletin [19] also advised that power lines in excess of 110 volts in cavities in which foams were applied should be shut off during application.

The potential of shock hazards due to moisture accumulation in dry ureaformaldehyde foam and cellulosic insulations under elevated temperatures was investigated by Clifton et al. [59]. The result indicated that shock hazards may exist if metal wall plates are used with ungrounded systems when in contact with moist thermal insulation. They recommended that thermal insulations which enter outlet or switch boxes during installation should be removed from them.

\subsection{FLAMMABILITY AND COMBUSTIBILITY}

Urea-formaldehyde foams are organic cellular insulations, and as such, are combustible materials and release heat when burned [5]. Although most urea-formaldehyde foam formulations do not support combustion readily, they do when exposed to the intensive heat of an extensive fire [65]. Model building codes in the United States require organic cellular insulations to have a maximum flame spread classification (as determined according to ASTM E 84) of 75 and to be protected by a layer of gypsum board of $1 / 2$ inch thickness or greater, or an equivalent fire barrier [1]. Most of the standards in table 1 have requirements with regard to flammability. The ASTM standard [17] has a maximum flame spread classification of 25 which is more stringent than the requirement of model codes for flame spread classification. Although recent data have not been found describing the results of tests conducted to show conformance to the flame spread requirement in the ASTM Standard, earlier available information indicated that in general foams can meet the recommended flame spread classification of $25[5]$.

In Canada, it has been found that formulation changes initiated to improve other properties such as shrinkage resistance have produced foams having flame spread classifications greater than those acceptable by code regulations for residential constructions [44]. In some cases it has been reported that the foams had flame spread classifications of 300 or more [44]. Data describing 
the effect of formulation and additives on the combustibility of foam have not been reported in the literature.

Another concern associated with the combustibility of urea-formaldehyde foam insulations is the toxicity of combustion products. Since the density of foam insulation is low and the mass in cavity walls is limited, the quantity of combustion products released by the foam during a fire would also be limited. In one study, it was found that a urea-formaldehyde foam released hydrogen cyanide at temperatures between about 840 to $1380^{\circ} \mathrm{F}\left(450\right.$ to $750^{\circ} \mathrm{C}$ ) and that the amount increased as the temperature was increased [66].

\subsection{FUNGUS RESISTANCE}

The ability of urea-formaldehyde foam insulation to resist the growth of fungus is a critical performance factor, because of damage which may occur to the residence or problems which may be experienced by the occcupants if fungal spores released from foam enter residences. In the early 1970s, claims were made that foams were resistant to fungal growth, but data were not available in support of those claims [5]. More recent experiences, particularly in Canada, have indicated certain installations where fungus growth on foam has been extensive $[11,44]$. Such growth was observed to occur during the time the freshly-installed foam remained wet after application. In some cases the fungus was described as living on the foam, while in others, it was described as being hosted by the foam.

Although fungus growth has been observed, the incidence of such problems in service has not been determined. Shirtliffe [11] has indicated that the incidence is less than that of cases of excessive formaldehyde emissions. In observing a limited number of cases of foam removal from cavity walls in Canada, Clerk [45] found that occurrences of fungus in the cavities were rare. The houses in the study were generally located in Montreal in Quebec Providence, Canada which is an area where the CMHC survey [64] predicted a low incidence of moisture related problems in housing. Field tests conducted in the United States did not report the presence of fungus attributed to the presence of foam $[41-43]$.

Shirtliffe [11] has described circumstances that may lead to fungal growth. He has indicated that, although formaldehyde may suppress the growth of wood rot fungus and other common fungi in cavities, under some circumstances, it may allow the growth of less common fungal species. These less common species might not normally survive in the cavities if the common fungi were present. Shirtliffe further indicated that the less common species may attack wood at lower moisture contents and not become dormant when the wood dries. Several species of fungus that use urea-formaldehyde foam as food and that are not affected by formaldehyde have been identified [11]. Fungi identified in foam include [31]:

Trichoderma harianum, Rifai aggr. (tentative identification), Cladosporium resinae (Lindau) de Vries, Penicillium roqueforti, Thom Series, Penicillium near spinulosum, Thom series, 
Paecilomyces varioti Bainier, and

Paecilomyces farinosus

The Cavity Foam Bureau (England) provided reports describing tests conducted to determine the resistance of urea-formaldehyde foam to fungus attack [67]. Fungi used in the tests were:

Chaetomium globosum
Cladosporium cladosporioides
Paecilomyces varioti
Penicillium expansum
Stachybotrys atra
Aspergillum niger

When foam specimens were suspended in these fungal medium alone, no evidence of fungal growth was observed on the foam. It was concluded that the foam was immune to attack by those fungi under those conditions. In another case where the foam specimens were sandwiched between plywood boards during exposure, fungal growth was evident on the plywood and surface of the foam specimens. Fungal growth had not penetrated into the foam specimens. It was suggested that the fungal growth on the surface had occurred because of nutrients which leached from the plywood under the moist conditions necessary for fungus incubation.

Recently, the effect of Serpula lacrymans on urea-formaldehyde foam was examined in Denmark [68]. It was found that the fungus damaged the foam and used it as a source of nitrogen and carbon. More importantly, it was observed that the foam provided a medium for rapid spread of the fungus in the building construction.

Many standards for urea-formaldehyde foam insulation (table 1) have requirements for fungal growth resistance. Reports describing the adequacy of these requirements for determining which foams would not be susceptible to fungus growth in service were not found during this study. It is conceivable that fungal growth in foamed cavities in European countries such as Great Britain or the Netherlands may have minimal likelihood of occurring, because the cavities are constructed of primarily masonry and not wood. The Canadian experiences with fungal growth in foam cavities may imply that the Canadian standard was inadequate for evaluating foams for resistance to fungus growth. In this regard, the ASTM standard (table 1) contains no test requirement for fungal growth resistance, because it was considered that no adequate test procedure existed to evaluate the property [17]. In lieu of a test procedure the ASTM standard includes a caveat to indicate that fungal growth was possible in cavities where foam was applied and remained wet for extended periods of time. It was also stated that buildings to be insulated with urea-formaldehyde foam should be constructed in a manner to permit the foam to dry in as short a time as possible.

Recent research at the National Research Council, Canada, has resulted in renewed interest concerning the importance of fungal growth resistance as a factor affecting the performance of urea-formaldehyde foam insulation [69]. For example, NRC research staff have found Stachybotrys alternans fungus in 
foam samples removed from some houses. Such findings have indicated a need to better define test methods and factors which affect the growth of fungus in insulated wall cavities.

\subsection{OFFGASSING AND RELEASE OF PARTICULATES}

Offgassing of formaldehyde from foam insulations was the primary reason why foam was banned in the United States. Offgassing and release of particulates are discussed in section 4 of this report.

\subsection{QUALITY CONTROL OF COMPONENT MATERIALS}

Since urea-formaldehyde foam insulations are produced on-site at the residences where they are installed, factory-conducted quality control methods cannot be employed. The resins and foaming agents used on-site to produce the insulation should meet acceptable criteria for quality assurance, since materials of unacceptable quality may produce poor quality foam insulation. Quality control of resins and foaming agents means that the physical and chemical properties of these freshly-produced components are the same, within prescribed limits, from batch to batch. The standards which have been developed in North America (e.g., Canada, DOE, ASTM, HUD) do not in general contain quality control requirements for component materials. The U.S. Department of Energy proposed quality control requirements for foam resins for incorporation in the interim material standard [12]. However, the incorporation of these requirements in the DOE interim standard did not occur since DOE withdrew it. The resin properties considered were viscosity, specific gravity, $\mathrm{pH}$, extractable methylol and aldehyde content. It was considered that these properties were measures for determining that during the resin production the chemical reaction between urea and formaldehyde proceeded as intended, and that variations between batches had not occurred [12].

\subsection{RAIN PENETRATION}

Rain penetration through insulated masonry cavity walls has been a major concern in European countries [70-73]. The extent of rain penetration of the outer leaf depends on its absorption capacity, the quality of the joining, and on the severity and duration of the driving rain [70]. In a properly-constructed cavity without insulation, water which may penetrate the outer leaf in general flows freely down its inner surface to the bottom of the cavity where it is deflected outwards. When the cavity is filled with insulation, the free flow of water down the inner surface of the outer leaf may be hindered and flow across the cavity may be promoted. One path of water flow across the insulated cavity is through gaps, voids, and cracks which may be present in the insulation. This has occurred with installed urea-formaldehyde foam whereby fissures created by foam shrinkage have provided bridges for water to cross from the outer leaf to inner leaf. Because of the severity of rain penetration problems in the United Kingdom, extensive research has been conducted by the Building Research Establishment in order to provide design and guide specifications regarding insulated cavity walls [71-74]. The British standard for foam application [21] restricts its installation in areas of severe wind driven 
rain depending upon the type of masonry. An exception is where the outer leaf has adequate rain protection through rendering or cladding.

\subsection{SHRINKAGE}

\subsubsection{The Extent of Shrinkage}

Urea-formaldehyde foam insulations shrink after installation during drying, and often for some period of time after drying. As the foam shrinks, gaps, cracks, and other voids are created between wall components and the foam, or within the foam, providing unwanted paths for increased heat flow and thus lowering the insulating properties of the foamed wall [38]. Variables impacting on foam shrinkage after application under typical ambient temperature and humidity conditions have not generally been investigated. In general, a better understanding of shrinkage processes of aqueous-based foams is needed. It has been shown that reversible expansion and contraction of about 3 percent occurs when humidity changes take place [40]. Timm [75] and Wulken [48] have listed possible factors affecting shrinkage including the chemical formulation, ratio of resin to foaming agent during application, the foaming equipment used, workmanship during application, the rate of drying of wet foam after application and the temperature during drying. Some urea-formaldehyde foams, upon exposure to combined elevated temperature and humidity conditions, undergo shrinkage through a mechanism involving reticulation of the cells [28] Reticulation was not observed to have occurred during shrinkage of foams at ambient laboratory conditions.

The extent to which foams undergo shrinkage has been a controversial subject [5]. Early literature indicated that manufacturers claimed the extent of shrinkage to be about 1-3 percent, but limited field observations at that time produced evidence that shrinkage was generally greater, in some cases approaching values of 8-10 percent. For example, Burch and Hunt [55] reported shrinkage of a foam sample in a test house to be about 8 percent, occurring over a period of 2 years. Since the mid-1970s, data have been developed from field surveys to support the earlier observations that foams generally shrink in service more than 1-3 percent. Bowles and Shirtliffe [40] reported that field observations in Canada found shrinkage to be generally between 3 and 8 percent, but as high as 11.5 percent. In one study Spinney and Weidt [43] found that foam shrinkage in 12 homes ranged from 2.5 to 9 percent, averaging 4.5 percent. In another study, Weidt et a1. [42] reported the average shrinkage in 17 homes to be 6 percent with a range of 4 to 9 percent. In this study, foam in 4 other homes had split and cracked to such an extent that the percent shrinkage could not be determined. In another study of foam in more than 30 homes, Tsongas et a1. [41] found the average shrinkage was about 8-10 percent, depending upon the foam dimension. Firstman [76] found that for 26 homes the values of foam shrinkage ranged from less than 1 to over 7 percent. In these field studies noted above, the foam samples were in general older than 2 years when the shrinkage measurements were made. Additionally Wulkan [48] has measured an average shrinkage of 7.8 percent for 39 specimens, but the ages and moisture contents were not given. In the case of all studies mentioned above, it is noted that comparisons of absolute shrinkage values should be made with caution, since foam may reversibly shrink and expand depending upon humidity conditions. 
The conditions for which shrinkage measurements are made are often not recorded.

Standards for foam insulation have requirements that under test conditions a freshly prepared specimen should not undergo shrinkage in excess of a specified percent in a given period of time (table 1). In North America, the Canadian standard [13] and the HUD bulletin [19] specified that the shrinkage should not exceed 4 percent in 28 days. The ASTM standard [17] specified that the shrinkage should not exceed 4 percent over the period of time required for the foam to dry to constant weight. These requirements are considered applicable to quality control only, since foams have been shown to undergo shrinkage greater than 4 percent in service. A methodology has not been developed to predict on the basis of laboratory tests the extent of shrinkage which a foam will undergo in service.

\subsubsection{The Effect of Shrinkage on Thermal Performance}

The extent to which shrinkage of foam insulation reduces the thermal efficiency of insulated walls depends upon the amount of shrinkage which occurs and the orientation of the cracks and gaps which result [31, 44]. Shirtliffe has indicated that the vertical shrinkage gaps along the studs are more important in reducing thermal efficiency than the horizontal gaps which occur in the foam [44]. The Canadian standard [13], DOE standard [18] and HUD bulletin [19] provided guidelines as to the effect of shrinkage on the efficiency of foaminsulated walls (table 1). In this regard, these standards used the term "effective thermal resistance" to indicate the calculated reduction of the laboratory measured value of the thermal resistance of the foam which is determined by a thermal conductivity test. This recognizes that the thermal efficiency of an insulation is based on simulated in-use conditions and not thermal conductivity alone. The Canadian standard indicated that foams in typical wood frame construction would be expected to shrink in service about 7 percent, resulting in an effective thermal resistance of the foam of 40 percent less than the thermal resistance determined by the thermal conductivity test [13]. The HUD bulletin [19] stated that 6 percent shrinkage would be expected in service and would result in an effective thermal resistance of the foam of 28 percent less than that based on the laboratory measured thermal conductivity value. The HUD Bulletin [19] also presented a plot estimating the effective thermal resistance of the installed foam as a function of the percent shrinkage. The DOE interim standard [18] indicated that the effective thermal resistance of foam should be taken as 30 percent less than that of the laboratory determined thermal conductivity value without considering the extent of shrinkage. The effective thermal resistances given in the HUD and DOE documents were also for wood frame construction. It is noted that the effective thermal resistance of $3.5 \mathrm{in.}(90 \mathrm{~mm})$ of foam, having a thermal resistance ( $R$-value) of about 4.1 units per inch and subjected to a derating of 30 percent, would be about 10 . This is about 15 percent less than the thermal resistance of a fibrous glass batt having an $\mathrm{R}$-value of about 11.5 .

The guideline concerning the effective thermal resistance of foams in service given in the Canadian standard was based on a summary of existing literature information [40]. For the HUD bulletin, the guideline on effective thermal resistance was based on a calculation for predicting the effect of air 
gaps on reducing the thermal efficiency of insulated walls [77, 78]. In spite of these guidelines for effective thermal resistance in standards, there is not general agreement in the literature that shrinkage reduces the insulating ability of foams. Timm and Smith [75] have made reference to calculations by Barker indicating that shrinkage has little effect on insulating ability of foams.

Since the publication of the Canadian [13] and DOE standards [18] and HUD bulletin [19], studies have been conducted which provide data supporting the guidelines for effective thermal resistance given in these documents. Reliable determinations of heat flow through building envelope components such as walls are made using calibrated or guarded hot box tests. Two of the studies on effective thermal resistance used hot box techniques. In one, the National Research Council, Canada, conducted a study of full scale walls filled with foam [79]. The foam was allowed to shrink in the walls and their thermal resistance was determined. The results indicated that, for example, if the foam shrunk 6 percent, the reduction in the thermal resistance was about 29 percent. In the second study, Tye and Desjarlais [80] measured the resistance of wood-frame cavity walls containing polystyrene boards of varying dimensions (to simulate shrinkage) and found a direct relationship between thermal performance of the wall and air gap around the polystyrene boards. For each 1 percent shrinkage, the reduction in thermal resistance of the insulation was about 5 percent which was comparable to the NRC results. In a related study, McFadden et a1. [81] conducted a field test using a small structure having walls insulated with urea-formaldehyde foam. The foam underwent a shrinkage of about 6 percent, which resulted in a measured thermal resistance of the wall which was about 20 percent less than that predicted without shrinkage. The effective thermal resistance of the foam was calculated to be about 29 percent less than the $\mathrm{R}$-value measured in the laboratory.

The U.S. Federal Trade Commission (FTC) reviewed available information concerning shrinkage and its effect on thermal efficiency in 1978 [82]. This review was undertaken by FTC because of concerns over misleading statements in advertisements regarding the $\mathrm{R}$-values of foam insulation. Based on the review, the FTC considered that shrinkage is an inherent characteristic of urea-formaldehyde foam insulation which can significantly reduce the $R$-value of the insulated area. Consequently, the FTC's insulation advertisement rule requires a disclosure statement on shrinkage or a reduction in the claimed $\mathrm{R}$-value to account for shrinkage, whenever ads for the product mention its R-value [83]. The required disclosure statement is as follows:

"Foam insulation shrinks after it is installed. This shrinkage may significantly reduce the R-value you get."

This statement need not be made if a manufacturer's literature claims a lower $\mathrm{R}$-value than that measured in the laboratory. However, the claimed lower R-value must be based on "reliable scientific proof of the extent of shrinkage and of its effect on R-value [83]." 


\subsection{TEMPERATURE AND HUMIDITY EFFECTS ON FOAM}

Urea-formaldehyde foam insulations are susceptible to hydrolytic degradation $[84,85]$. Hydrolysis is the chemical reaction of the urea-formaldehyde polymer with water, resulting in polymer degradation [5]. Hydrolysis may result from exposure of foams to temperature and humidity conditions encountered in service. The effects of temperature and humidity exposure on foams may be variable depending upon the composition of the foam, with some foams being more stable than others under severe temperature and humidity conditions [27, 83].

Under some combined temperature and humidity conditions foam specimens may undergo shrinkage, mass loss, reduction in mechanical properties, and in severe cases disintegration [5]. Also, hydrolytic degradation of foams under temperature and humidity exposure may he accompanied by an emission of formaldehyde (see section 4). Field studies in the United States found no extensive deterioration of inspected foams attributable to temperature and humidity exposure [41, 42]. The nouses inspected in these U.S. studies were not located in areas that experience the longest periods of warm humid weather. The Finland Technical Research Center has reported that disintegration of foam insulation due to temperature and humidity exposure has occurred in practice, hut only in a few exceptional cases [34]. As previously indicated (section 3.4), limited evidence from Canada has shown examples where foams have become powdery, friable, or even collapsed to powder during in-service aging.

Rossiter et al. [27] and Tye and Desjarlais [80] in separate studies investigated mass and volume losses upon temperature and humidity exposure of foams which were commercially available in the late 1970s. In these studies, foam samples were prepared in simulated cavities made of $2 \times 4$ studs and plywood. Upon removal from these cavities, the foams were exposed to various combinations of temperature and humidity. Their results indicated that for some foams the amount of shrinkage (loss of volume) increased as the intensity of the temperature and humidity conditions increased. In one case a foam sample underwent volumetric shrinkage in excess of 50 percent at conditions of $60^{\circ} \mathrm{C}\left(140^{\circ} \mathrm{F}\right)$ and 75 percent relative humidity, while another sample shrank about 5 percent under the same conditions [27]. Tye and Desjarlias [80] also showed that excessive shrinkage of the foam was accompanied by loss in its compressive strength. Both studies indicated that foams can shrink excessively and not experience a significant change in mass. Excessive shrinkage with little change in mass has been attributed to the reticulation (1oss of cell walls) of the foam [27]. The cell walls contain only a small percentage of the mass of the foam. When foams were exposed to elevated temperatures of $120-140^{\circ} \mathrm{F}$ $\left(50-60^{\circ} \mathrm{C}\right.$ ) under dry conditions (which prevent hydrolysis), relatively little volumetric shrinkage was observed. Bowles and Shirtliffe [40] have reported that temperature cycling and rate of temperature changes at low humidity levels result in about 3 to 5 percent shrinkage. Investigations have not been conducted to determine whether such exposures produce a degradation in the cellular structure of the foam.

The acidity of the urea-formaldehyde foam is also an important factor influencing the hydrolytic degradation [84, 85]. In a study on the factors influencing long-term stability, Allan et al. [84] have shown that acid-free foam is less 
susceptible to hydrolytic degradation than foam which contains the acid catalyst is present.

Stable foams that do not appreciably shrink, crack, or crumble under temperature and humidity exposure are obviously more suitable as insulations than those that do undergo such deterioration [27]. The ASTM standard [17] contains a requirement for testing the temperature and humidity resistance of foam (table 1). During the test, the specimen should not shrink by more than 4 percent linearly. The test conditions are exposure of the specimen to $150^{\circ} \mathrm{F}\left(66^{\circ} \mathrm{C}\right)$ and about 10 percent relative humidity for 7 days, followed by exposure to $100^{\circ} \mathrm{F}\left(38^{\circ} \mathrm{C}\right)$ and 75 percent relative humidity for 28 days. The relationship between this test and in-service performance has not been established. In comparison with the findings of Rossiter et a1. [27] concerning temperature and humidity resistance of foam, this ASTM procedure may be inadequate. First, these authors demonstrated that a foam which is susceptible to shrinkage under elevated temperature and humidity conditions may experience little shrinkage at low humidity conditions. Thus, the step in the ASTM procedure for heat aging at about 10 percent humidity may be inappropriate. Secondly, Rossiter et al. [27] showed that a temperature and humidity susceptible foam may undergo relatively little shrinkage in 28 days exposure at $40^{\circ} \mathrm{C}\left(104^{\circ} \mathrm{F}\right)$ and 75 percent relative humidity. Thus, this second exposure step in the ASTM procedure may be too short and the intensity of the exposure conditions may be too mild. Even in this case no relationship between service life and test results have been established.

\subsection{THERMAL CONDUCTIVITY}

Laboratory-measured values of thermal conductivity of urea-formaldehyde foam insulations are generally less than those of mineral fiber and cellulosic retrofit insulations $[42,55]$. Thermal conductivity values of urea-formaldehyde foam insulations may be variable depending upon factors such as the test method, mean temperature of the test, foam density, and moisture content [5]. Ce11 size and cell wall incegrity are also important parameters. Shirtliffe has indicated that the thermal resistance values of foams are reduced as cell walls of the foam break [44].

In spite of the extensive use of these insulations in the late 1970s, a design value for thermal conductivity has not been included in the ASHRAE Handbnok of Fundamentals [86]. However, guidelines are provided by ASHRAE [86] for the range of expected values of thermal conductivity. NBS has recommended that for design purposes the thermal conductivity value for foams be taken as $0.24 \mathrm{Btu} \cdot \mathrm{in} \cdot / \mathrm{h} \cdot \mathrm{ft}^{2} \cdot{ }^{\circ} \mathrm{F}(0.035 \mathrm{~W} / \mathrm{m} \cdot \mathrm{K})$ at $75^{\circ} \mathrm{F}\left(24^{\circ} \mathrm{C}\right)$ [5]. This value agreed well with a number of measurements made in Canada and other countries. The NBS report also indicated that comprehensive interlaboratory tests by an organization such as ASHRAE might result in a design value of thermal conductivity which would supersede the NBS recommended value, since the NBS recommendation was based on test results from one foam specimen only. It is important to keep in mind that the thermal performance of foam insulation in a wall may be less than indicated on the basis of 1aboratory measurements of thermal conductivity. As discussed in section 3.12.2, the shrinkage of foam results in an effective thermal resistance which is less than the laboratory determined 
value. The NBS recommended design value for thermal conductivity did not consider the effects of shrinkage but was based on a laboratory test of thermal conductivity [5].

Weidt et al. [42] determined the thermal conductivity values of 24 specimens removed from the walls of residences. The values ranged from 0.22 to 0.33 Btu $\cdot$ in. $/ \mathrm{h} \cdot \mathrm{ft}^{2} \cdot{ }^{\circ} \mathrm{F}(0.032$ to $0.048 \mathrm{~W} / \mathrm{m} \cdot \mathrm{K})$, with an average value of 0.25 Btu.in./h・ft ${ }^{2} \cdot{ }^{\circ} \mathrm{F}(0.036 \mathrm{~W} / \mathrm{m} \cdot \mathrm{K})$. It was also found that as the density of the foam samples in this field study increased, the thermal conductivity values tended to decrease. The average value of thermal conductivity for the 24 foam specimens compared favorably to the NBS recommended design value of 0.24 Btu $\cdot$ in. $/ \mathrm{h} \cdot \mathrm{ft}^{2} \cdot{ }^{\circ} \mathrm{F}(0.035 \mathrm{~W} / \mathrm{m} \cdot \mathrm{K})$ 。

\subsection{WATER ABSORPTION}

Moisture accumulation within thermal insulation, whether it be foam or any other type, may adversely affect the thermal performance of the insulated wall or result in deterioration of wall component materials. As previously indicated, urea-formaldehyde foams are applied wet in cavities where they should dry and not re-gain excessive quantities of moisture over time. As the moisture content of a foam increases, the thermal conductivity increases. Moreover, with other factors being equal, a foam which gains relatively large quantities of moisture can be more susceptible to hydrolytic degradation than a foam which absorbs less moisture. Moisture content measurements have been made of foam samples removed from walls of residences in the United States. In general these samples were installed a minimum of two years before the field surveys. The results indicated that the moisture content of the field samples was in general comparable to that expected on the basis of conditioning foams under controlled laboratory conditions. Tsongas et al. [41] found that the moisture content (by dry weight) of 159 samples taken from homes in the Pacific Northwest ranged from 6 to 22 percent with an average value of 12 percent. Weidt et a1. [42] measured the moisture content of 24 specimens which ranged from 3 to 22 percent and had an average value of 12 percent. In this study the houses were located in the Midwest, Northeast, and Mid-Atlantic regions of the U.S. Spinney and Weidt [43] found that the moisture contents of 12 samples from houses in Minnesota ranged from 1 to 12 percent. Data summarized from the literature where foam samples were conditioned under controlled laboratory conditions have indicated that the moisture contents of foam have ranged from 8 to 18 percent depending upon the exposure conditions [5].

Standards (table 1) have incorporated requirements for moisture absorption through capillarity. The test procedures are conducted on freshly prepared foam which has dried. By way of example, the procedure in the ASTM standard [17] involves floating specimens on water for seven days and determining the quantity of water absorbed. To meet the requirements of the standard, the water absorption by the foam sample should not exceed 15 percent by volume. Little data have been published in the literature describing the performance of foam samples in this capillarity absorption test.

In general tests under isothermal conditions show that the capillarity moisture absorption of foams is slight, although under pressure the foams may absorb 
large quantities of water $[5,34]$. Water absorption due to moisture drive through the foam may be larger. Shirtliffe [44] has indicated that although foams may be hydrophobic when first produced, in some cases hydrolytic aging in service may alter the foams such that they become hygroscopic and may absorb large quantities of moisture. Such foams would be more susceptible to hydrolysis and thus the emission of formaldehyde. Weidt et al. [42] measured the capillarity water absorption of 13 foam specimens which were at least 2 years old and removed from walls of houses. The specimens had a variable surface described as ranging from normal and firm to yellow, powdery, and slightly friable. Of the 13 specimens, one absorbed more than 15 percent moisture by volume and the majority absorbed less than 5 percent by volume. The specimen which absorbed more than 15 percent by volume was described as having normal surfaces without signs of deterioration. 


\section{RELEASE OF FORMALDEHYDE, OTHER GASES, AND PARTICULATES}

It has been well established that urea-formaldehyde foam insulations release formaldehyde which can permeate or be transported into the air of residences $[7,9]$. Many studies have dealt with permeation alone. A review of the effects of formaldehyde on occupants of residences is beyond the scope of this report. They have been reviewed elsewhere $[4,7,9,87,88]$.

The potential for urea-formaldehyde foam to release formaldehyde or other gases is a critical factor affecting its performance as a thermal insulation. The potential for offgassing should be taken into consideration when the suitability of the foam for its intended use is being assessed. For example, offgassing potential should be addressed in standards developed for urea-formaldehyde foam insulations. This section of the report provides an overview of information on formaldehyde release by foams. In addition, a summary of information concerning release of gases other than formaldehyde as well as particulates is given. Concerns that some foams may release other gases and particulates have been recently raised $[89,90]$.

The release of formaldehyde, other gases, and particulates from foam into residences may be considered, in a broad sense, as a factor impacting on indoor air quality [91]. The science and technology of defining indoor air quality is in its early stages of development and many gaps are present in the knowledge of this subject. For example, agents contributing to poor indoor air quality have in many cases not been identified, methods for low-level detection of these agents may not be always satisfactory, and exposure guidelines regarding their effects on occupants may not be well defined [92, 93].

\subsection{FORMALDEHYDE RELEASE}

\subsubsection{Formaldehyde Leve1s in Residences}

In 1982, the U.S. Consumer Product Safety Commission (CPSC) concluded that residences insulated with urea-formaldehyde foam had on the average higher levels of formaldehyde than those found in other residences or outdoors [7]. The cause of these increased formaldehyde levels was attributed to the presence of the foam. CPSC also stated that it was not disputed that many foam-insulated residences have relatively low formaldehyde levels [7]. Because formaldehyde release from foam has been a key issue concerning its use as a thermal insulation, numerous measurements of formaldehyde levels in residences with and without foam insulation have been made in the last few years. Many of the measurements were carried out as part of studies aimed at understanding the effect of foam on indoor air quality $[30,36,94-96]$. In other cases, formaldehyde measurements have been made by state and local authorities who were responding to homeowners' complaints related to the presence of urea-formaldehyde foam in their residences [7].

The CPSC analyzed data on formaldehyde levels in 1,164 residences which contained urea-formaldehyde foam and 103 residences without foam [97]. Data included measurements in foam-insulated houses from a few weeks after installation to 9 years after installation. The data analyzed by CPSC indicated that the average 
level of formaldehyde in residences with urea-formaldehyde foam was $0.12 \mathrm{ppm}$, while that in residences without foam was $0.03 \mathrm{ppm} \mathrm{[7].} \mathrm{The} \mathrm{analysis} \mathrm{also}$ indicated that the level of formaldehyde in foam insulated residences declined relatively rapidly in about the first 40 weeks after installation and more slowly after that time. For example, within 40 weeks after installation, the formaldehyde levels were generally in range of $0.2-0.3 \mathrm{ppm}$, while about 1 year after installation they dropped to slightly less than $0.1 \mathrm{ppm}$ on the average [97]. This CPSC analysis did not consider moisture in the walls and foams and its effects on formaldehyde release.

The Canadian Urea-Formaldehyde Foam Insulation Information and Coordination Centre (UFFI Centre) conducted a survey to evaluate the extent and seriousness of problems, including indoor formaldehyde concentrations, associated with the installation of foam in Canadian residences [94]. The total number of residences tested was 2,311 which included 383 control homes not having foam insulation. The foam had generally been installed in these homes at least 10 months and in many cases for much longer periods of time. In the UFFI Centre study, the average indoor level of formaldehyde in residences with foam was $0.054 \mathrm{ppm}$. For the control homes the level was $0.036 \mathrm{ppm}$. On the average, residences having foam in stud spaces had higher $(0.061 \mathrm{ppm})$ formaldehyde levels than those with foam between brick and sheathing ( $0.043 \mathrm{ppm})$ or between brick and brick $(0.050 \mathrm{ppm})$. Also, the percentage of homes with levels greater than $0.1 \mathrm{ppm}$ was higher for the foam insulated residences than for the controls.

In the UFFI Centre study, measurements were also made of formaldehyde levels in cavities, of moisture content in sill plates, and of water vapor in the wall cavities [94]. Analysis of the results indicated that the average value of the formaldehyde level in the indoor air generally increased as it increased in the cavity. In addition the average formaldehyde level in the cavity decreased with the age of the foam in an indeterminable way and increased with the water vapor level in the cavity.

A limited study was conducted in the United States whereby formaldehyde levels were determined in 3 control residences, one mobile home having urea-formaldehyde foam, 10 residences having urea-formaldehyde foam, and 2 residences from which foam had been removed [95]. These homes were located in Colorado and the age of the foam was greater than 2 years. The average formaldehyde level in the foam insulated homes was $0.039 \mathrm{ppm}$. That in the control homes averaged 0.019 $\mathrm{ppm}$. For two of the homes in the Colorado area, the formaldehyde measurements were made in both the winter and following spring. These results in general showed the levels to increase in the spring time.

This study also included measurements of formaldehyde levels of 11 foaminsulated residences located in Wisconsin [95]. Nine of these residences had urea-formaldehyde foam insulation with a minimum age of 2 years; the foam age of the other two residences was a year or less. The average formaldehyde concentration was $0.079 \mathrm{ppm}$, which was higher than that for the residences surveyed in Colorado. This apparent increase in formaldehyde level was considered to be due to the difference in ambient temperature and relative humidity of the two states [95]. 
Another study in the United States conducted to monitor indoor air quality of 40 residences included measurements of formaldehyde levels [95]. Approximately one fourth of these homes contained urea-formaldehyde foam. It was found that formaldehyde levels were highest in foam insulated houses and also those newlyconstructed. In the case of one foam-insulated home, formaldehyde levels were monitored once an hour for 32 hours. The results indicated that the formaldehyde level increased as the outdoor temperature increased during the day. The peak level was reached during late afternoon or evening. Then the level declined until the early morning.

The results of a study of 31 residences in England have been summarized by Barrett [36]. Formaldehyde levels in 17 residences without foam and 14 residences with foam ranging in age from 2 to 8 years were reported as not being significantly different. It was also indicated when urea-formaldehyde foam was first installed, the indoor air concentration of formaldehyde increased. The peak concentration was normally less than $0.5 \mathrm{ppm}$, which decreased to about $0.1 \mathrm{ppm}$ at the end of a year.

The Australian Experimental Building Station reported the results of measurements made in one Australian foam-insulated residence where the occupants had complained of an odor problem [30]. The measurements indicated that the level of formaldehyde was between 4.0 and $7.0 \mathrm{ppm}$ one week after installation. These levels dropped to $2.0 \mathrm{ppm}$ eighteen days after installation.

In general few studies have been reported in the literature describing the results of formaldehyde measurements made at the time of foam installation and again periodically as time elapsed. In the studies described above, the majority of measurements were normally made at one point in time and usually a number of months after foam installation.

\subsubsection{Formaldehyde Measurement}

As indicated by Meyer [10], formaldehyde sampling is complex and difficult because at room temperature it slowly equilibrates between three phases: the gas, the liquid, and the solid. Factors contributing to the sampling complexity include formaldehyde's affinity for water and tendency to form hydrogen bonds. Because of its affinity for water, formaldehyde may accumulate on moist surfaces and be re-released as these surfaces lose moisture.

The measurement of formaldehyde levels in indoor air is further complicated by the fact that the air is not normally in equilibrium with the formaldehyde source [10]. According to Meyer [10], parameters influencing the measurements include contact time between air and source, tota1 air volume, humidity, moisture on the surface of the source, and absorption of the formaldehyde on other surfaces. Other parameters influencing the measurements include temperature gradients and changes with time. Matthews et al. [98] have been developing mathematical models to estimate formaldehyde levels as influenced by environmental conditions (temperature, humidity), product loading, ventilation parameters, product emission rate, and formaldehyde concentration in the space. However, these models deal primarily with particle board or sources of formaldehyde in the room, and not with urea-formaldehyde foam in cavities. 
Many analytical methods are available for measuring the formaldehyde level of air $[99,100]$. An evaluation of the existing analytical methods in 1981 indicated that substantial problems involving calibration, sampling, or method of analysis existed with most of the methods [99]. Because of current interest concerning formaldehyde as an indoor air pollutant, recent studies have been conducted to improve the reliability of test methods [101-105]. The methods may be generally classified as active whereby air is pumped through a sampling medium such as water-reagent solution to collect the formaldehyde, or passive whereby the formaldehyde is collected using a dosimeter. In both cases, the collected formaldehyde sample is normally returned to a laboratory for analysis. On-site techniques using colorimetric indicator tubes for approximating formaldehyde levels are also available. These indicator tubes have been used extensively in Canada for estimating formaldehyde levels in wall cavities [94]. Also, an on-site spectrophotometric method has been recently developed in Canada.

The National Research Council, Canada, has been conducting an extensive research program to develop improved methods for determining low-levels of formaldehyde in indoor air [101, 106]. The program has included both laboratory and field studies. Comparative testing of formaldehyde levels using different active and passive techniques have been carried out, as well as studies designed to investigate the various parameters which influence the results of individual tests. In addition, other studies have been conducted to develop new techniques for measuring formaldehyde levels. Investigations of the reliability of dosimeters for determining low levels of formaldehyde in indoor air have been a major component of the NRC studies. An advantage to using dosimeters is that they give a time-weighed average reading of formaldehyde, which may be Cesirable since formaldehyde levels in foam-insulated homes can be widely variable with time of day or season [106]. Another advantage of dosimeters is their lower cost in comparison to the costs of using active methods. Dosimeters may be mailed to a homeowner, exposed in a residence for the specified time period, and returned by mail to the laboratory for analysis. Care must be exercised to follow exactly the recommended procedures for use and to avoid contamination during use and shipment. The results of the NRC studies including recommendations on use of dosimeters are expected to be soon published [101].

Guidelines which consider factors such as the test method, number of determinations, and sampling conditions are not available in the United States to assist the homeowner in the measurement of formaldehyde. Such guidelines would be useful to help assure the validity of the measurement because of its complexity. Measurement results are influenced, among other factors, by occupant living habits and seasonal effects. If only one sample is taken in a home at a particular point in time, there is no way of knowing how that measurement relates to range of levels in the residence and whether that sample is typical of the concentration present over time [7].

The Canadian UFFI Centre makes formaldehyde level measurements of all homes upon their entry into the Canadian-government assistance program [107]. The measurements are made using dosimeters. In general, the dosimeters are sent to the homeowners who expose them, and then in return, send them to a laboratory for analysis. The results of the analysis are sent to the UFFI Centre. Early in the program some measurements were made using active air sampling techniques. 
The UFFI Centre has prepared a protocol for the active measurements of formaldehyde in homes insulated with foam [107]. The procotol includes steps to be taken to condition the residence for 18 hours before the measurements are made, the types of measurements to be made, and the locations of the sampling. The conditioning of the house involves closing it up as much as possible, setting the temperature to a minimum of $20^{\circ} \mathrm{C}$, and turning down the humidifier setting (whenever one is operating). The protocol emphasizes that during the 18 hour conditioning ventilation devices should not be used, smoke should not be generated (e.g., frying, broiling, smoking, fireplaces), automobiles should not be operated in attached garages or carports, paints and related materials should not be used, and doors to the exterior not be opened (when necessary, exit or entry should be as quick as possible).

\subsubsection{Mechanism of Formaldehyde Release}

In studying the problem of formaldehyde release by urea-formaldehyde foam insulations, the CPSC concluded that the mechanism for release was not understood [7]. Meyer [10] has indicated that the release is complex but did not address the factors which contribute to the complexity. Allan has stated there is a general lack of knowledge concerning the chemistry of urea-formaldehyde resins [108]. A few laboratory studies, as summarized below, have been conducted to investigate the formaldehyde release mechanism. In Canada, the NRC is extensively pursuing studies to characterize urea-formaldehyde foam with regard to release of formaldehyde and the factors affecting the rate of release, level, hydrolysis rate, and storage of formaldehyde on foam surfaces [69]. The results of these ongoing NRC studies are not yet published.

Meyer has presented a general review of the hydrolytic degradation of urea-formaldehyde resins and the factors which contribute to the release of formaldehyde from them [10]. Initial studies on foam insulation regarding formaldehyde release indicated that the emission could occur by two pathways: (1) an initial, short-term burst (a few days) caused by release of freeformaldehyde or the hydrolysis of chain-end $\mathrm{N}$-methylol groups of the polymer; and (2) a slow longer-term evolution caused by degradation of the polymer backbone [84, 109]. It was found that foams emit formaldehyde under ambient temperature and humidity conditions. An increase in either the temperature or humidity results in an increase in the level of formaldehyde released [33, 109]. The inherent acidity of the foam has been considered to be a critical factor affecting long-term release and polymer backbone degradation [84]. Foam specimens which were washed with water until the wash had a neutral pH were less prone to emit formaldehyde than those which were not water washed.

Freshly-prepared foams may produce an initial burst of formaldehyde. The initial burst has been often considered to be related to the amount of free formaldehyde present in the urea-formaldehyde resin from which the foam was produced [110]. The effect of drying of the fresh foam was not considered. It was assumed that low levels of free-formaldehyde in the resin would minimize the initial burst of formaldehyde release. This assumption accounts for the requirements in most of the standards given in table 1 that the free formaldehyde content of the resin should be kept within a relatively low specified limit. However, later studies have suggested that the assumption concerning the 
relationship between free formaldehyde in the resin and initial formaldehyde release is incorrect [110]. Rather, it has been proposed that the initial burst of formaldehyde is closely related to water content of the foam and the rate of removal of that water through the drying process. It was demonstrated, for example, that during drying, as the temperature is lowered and the humidity is increased (conditions which favor slow drying), less offgassing of the foam occurs. Similarly it has been reported that no relationship exists between the amount of free formaldehyde in the resin and the potential for foams to release formaldehyde over the long-term [25]. Release of formaldehyde over the long-term is related to the chemistry of the urea-formaldehyde polymer, and possibly to the physical chemistry of the polymer surface.

Some preliminary studies have been reported on the characterization of the structure of urea-formaldehyde foam and foam resins using nuclear magnetic resonance (NMR) spectroscopy and high performance liquid chromatography (HPLC) $[10,33,111,112]$. These studies were intended, in part, to identify labile groups which contribute to formaldehyde emission, and assist the development of improved products.

\subsubsection{Effects of Application Parameters on Formaldehyde Release}

Poor workmanship during installation has often been attributed as a cause of release of formaldehyde from foam insulations [33]. This supposition had been addressed in one study [33]. The results showed that although the formaldehyde release may be influenced by the application parameters, nevertheless foam insulations prepared using manfacturers' recommended procedures and equipment emitted formaldehyde under ambient environmental conditions. Factors examined in this study included the shelf life of the resin, temperature of the resins, hardness of the water (used to constitute dry resins), the ratio of resin to foaming agent, and the air pressure of the pumping system which effects the wet density of the freshly-formed foam.

\subsubsection{Formaldehyde Release and Standards for Urea-Formaldehyde Foams}

Requirements and test methods pertaining to the long-term release of formaldehyde from urea-formaldehyde foam insulations have not been included in consensus standards such as ASTM (table 1), as addressed in section 2. A proposed amendment to the West German standard [16] would require measuring the formaldehyde level in a test room (table 1 ).

The technical literature contains descriptions of test methods proposed to measure formaldehyde release from foams [113-115]. In general these tests involved placement of a foam specimen in a small chamber and sampling the formaldehyde level in the air surrounding the foam. It has been suggested that such a technique might have applicability as the basis for a standard method of test [112]. Investigations of the validity of such test methods for incorporation into voluntary consensus standards have not been reported. 


\subsection{RELEASE OF GASES OTHER THAN FORMALDEHYDE}

In considering homeowner complaints concerning the presence of urea-formaldehyde foam insulation, questions have been raised as to whether gases other than formaldehyde may be contributing causes to the problems [49]. The National Research Council, Canada, has indicated that a mixture of gases may be released by the foams [49]. It has been stated by NRC that the composition of the gases might vary among products and thus be difficult to analyze. The uncharacterized mixture of gases has been referred to as "UFFI gas" [49].

The National Research Council, Canada, has studies underway to identify gases other than formaldehyde released from foam [116]. Analytical techniques primarily being used for gas identification are gas chromatography/mass spectroscopy (GS/MS), and mass spectroscopy/mass spectroscopy (MS/MS). Results from these studies are not yet available. One Canadian report has stated that evidence is available that gases such as acetaldehyde, benzaldehyde, phenol, cresols, and methylnaphthalenes may be emitted from foams [9]. The report, however, was not certain as to the exact cause of the emissions, since it stated that the gases might be due to emission from the foam or from reaction of chemicals in the foam with other building materials. This Canadian report of other gases provided no interpretation of the significance of their presence. In England, Barrett has indicated that the British Building Research Establishment has been investigating the possibility of other gases being released from foams [117]. He reported that so far the only vapors found of significance have been formaldehyde and water vapor. It was not stated whether other gases were found. In the U.S., Timm has reported acetaldehyde emissions from foams $[118]$.

At the present time in the Canadian Assistance Program, only measurements of formaldehyde in residences are made. It is considered that the level of formaldehyde may be used as an indicator of the potential of "UFFI gas" to penetrate into the living space [63]. The National Research Council, Canada, is investigating methods for sampling other gases in indoor air of homes containing urea-formaldehyde foam [119].

\subsection{RELEASE OF PARTICULATES}

Particulate release from foams has also been considered as a contributing cause of complaints concerning the presence of urea-formaldehyde foam in residences. As foams age, their surfaces in many cases become friable and tend to release tiny particles as air moves across the surfaces, vibrations occur, or static changes develop. In addition, microscopy investigations have shown the presence of small spheroids within the cellular structure of the foam [120, 121]. Nantel [121] has conducted preliminary experiments to isolate these small particles through extraction with a water aerosol. The National Research Council, Canada, has research ongoing to characterize the composition of particulates released from foam, and to concentrate and sample the small spheroids for purposes of identification. Methods for differentiating between urea-formaldehyde foam particles and household dust are receiving special attention. Results of these research activities are not yet published. 


\section{REMEDIAL MEASURES}

\subsection{PRESENT PRACTICES}

The presence of urea-formaldehyde foam insulation in the walls of a residence may, under some circumstances, provide reason for a homeowner to take remedial actions because of concerns about release of formaldehyde, other gases, or particulates from the foam into the residence. The remedial actions which have been taken to date generally are intended to reduce or prevent the penetration of these gases and particulates into the living space. This section of the report presents a summary of information available concerning remedial actions. Most of the information presented has been obtained from Canada where the UJFFI Centre is administering the "Assistance Program for UFFI Homeowners" [122]. This program provides financial assistance for corrective measures which can be undertaken by contractors or by homeowners. Homeowners may select the corrective measures for their own residences. The prograin recognizes that expertise in conducting remedial actions is a necessity in obtaining success. Therefore, a training program has been established for contractors who conduct remedial actions. Contractors successfully completing the program are registered as such by the UFFI Centre. Homeowners who wish to conduct their own remedial measures may also take the UFFI Centre training program at no cost. In addition to the UFFI Centre program, an extensive research program is underway at the National Research Council, Canada, to characterize urea-formaldehyde foam insulation and its performance in residences, as well as to investigate the effectiveness of remedial measures which may be undertaken to alleviate problems associated with its presence in cavity walls.

Manuals and related documents for remedial actions concerning urea-formaldehyde foam insulation have been prepared. These include:

- NRC (Canada) Building Practice Note 19, "Urea-Formaldehyde Foam Insulation" [49],

- NRC (Canada) Building Practice Note 23, "Urea-Formaldehyde Foan Insulation: Problem Identification and Remedial. Measures for Wood-Frame Construction" [26],

- UfFI Centre (Canada) Training Manual on "Corrective Measures for Residences Insulated With Urea-Formaldehyde Foan Insulation (UFFI)" [123],

- NRC (Canada) Removal Document [124], and

- EBS (Australia) Technical Record 488 "Urea-Formalriehyde Foam Insulation: Problem Identification and Remedial Measures" [125].

These documents provide information concerning the procedures to be follonit in undertaking remedial actions. It is emphasized in these documents that individuals involved with remedial actions should be knowledgeable in thei. 
undertaking. The remedial action process may be summarized as involving a number of general steps and considerations:

- problem identification

- understanding the nature of urea-formaldehyde foam insulation

- understanding air and vapor movement in residences

- knowledge of the type of construction

- the types of remedial measures

- safety considerations during remedial actions

The remedial action documents mentioned above provide detailed information on each of these general steps. A brief description of each is given in the paragraphs which follow to provide an overview of the remedial action process. These descriptions are not intended to act as a substitute for the available remedial action manuals.

\subsubsection{Problem Identification}

Identification of the problem is an obvious first step for making the decision regarding the remedial measures to be taken to reduce the severity or cause of the problem [26]. The National Research Council, Canada, has recommended that an investigation into the cause of the problem yield information on the following:

1. The nature of the problem (e.g., formaldehyde, moisture),

2. Moisture content of the wood in cavities,

3. Concentration of formaldehyde gas in the insulated cavity and possibly the living space, and

4. The identification of cavities insulated with foam.

Knowledge of the moisture content of the wooden cavity members is desirable for two reasons. Increased levels of moisture can result in higher levels of formaldehyde release from foams and, if the moisture level is high enough, may provide for fungal growth in the cavity.

Measurements of formaldehyde gas concentrations in cavities are recommended because they provide an indication of the potential for high formaldehyde gas concentration in the living space. If the concentration of formaldehyde is high in the cavities, then air moving from the cavities into the living space can contain a high level of formaldehyde. The National Research Council, Canada, has proposed a simple relation to approximate the indoor air concentration of formaldehyde based on that of the cavity [26]:

$$
\mathrm{C}=(\mathrm{n} / \mathrm{m}) \cdot \mathrm{C}_{\mathrm{c}}
$$

where $C=$ the formaldehyde gas concentration in living space

$\mathrm{C}_{\mathrm{C}}=$ the formaldehyde gas concentration in the cavity 
$\mathrm{n}=$ the amount of air flowing from cavity into the space, and
$\mathrm{m}=$ the amount of air flowing from other sources into the space.

The development of this relationship includes a number of simplifying assumptions including: (1) no other sources of formaldehyde are present; the formaldehyde gas concentration in the cavity is constant, and ( 3 ) air flows are constant. Values for $(\mathrm{n} / \mathrm{m})$ may range from $1 / 15$ to $1 / 20$ for gypsum board walls, and from $1 / 25$ to $1 / 35$ for lath and plaster walls [26].

The measurement of formaldehyde gas in the living space is generally not sufficient to recommend a course of remedial action [26]. Such measurements can be quite variable and are dependent upon factors such as wind speed and direction, temperature, humidity, and occupant living habits. The initial ratio of the formaldehyde gas concentration in the living space to that in the insulated cavity is a benchmark which can be compared with measurements made after completion of remedial actions [26].

\subsubsection{Understanding the Nature of Urea-Formaldehyde Foam Insulation}

An understanding of the nature of urea-formaldehyde foam insulation is essential to increasing the awareness of the extent of any problems and recommending remedial actions to be taken. The physical characteristics, composition, method of manufacture, and proper and improper uses of the foam impact on methods of problem identification and remedial actions. For example, the foam was intended to flow during installation into hard-to-reach cavities of walls. Consequently, as long as it remained fluid for an adequate time, it may have flowed unsuspectingly into areas which should not have been foamed. In conducting remedial actions, to the extent possible, hidden areas of foam installation should be identified and then treated according to the selected course of action $[123,124]$.

\subsubsection{Understanding Air and Vapor Movement in Residences}

Both air and water vapor movement in residences influence problems associated with formaldehyde release from residences. Under some conditions water vapor may migrate from the warm interior of the house towards the cooler outside environment and accumulate in the foam installed in cavity walls [123]. Moisture migration through walls occurs by two pathways: diffusion and air leakage. This latter pathway is the more important of the two. Moisture accumulated in foam may accelerate degradation which is accompanied by a release of formaldehyde gas. Keeping moisture levels of foam as low as possible provides a form of remedial action.

Air movement inwards through walls transports formaldehyde gas into the residence [123]. A knowledge of air movements in residences contributes to the effective application of remedial measures [123]. Air in homes tends to flow from an area of high pressure to one of the low pressure. Factors affecting air pressure include stack effects, induced exhaust, natural ventilation, forced ventilation, and wind action. Thus, reducing air movement through walls to the living space also provides a means of remedial action. 


\subsubsection{Knowledge of the Type of Construction}

Knowledge of the type of construction containing urea-formaldehyde foam insulation is important to define the scope of work associated with the remedial actions to be undertaken [123]. It allows the identification of the types and locations of cavities where foam may be located. The UFFI Centre Training Manual [123] divides the types of construction into wood-frame or solid wall. Although solid wall construction contains no cavities per se, areas where foam could have been installed may have been created, for example, by the addition of furring strips and a cladding or other facing. Masonry construction also may be of the solid wall or cavity wall type.

The UFFI Centre Training Manual [123] provides drawings of wall profiles for the various types of constructions normally found in Canada. These drawings point out characteristics to help identify the type of wall construction. They also highlight cavities which may contain urea-formaldehyde foam as well as areas of the construction where foam may have unsuspectingly been installed. It is noted that in some cases, identification of the type of construction may not be possible without opening the wall from the exterior or interior [123].

\subsubsection{Types of Remedial Measures}

The types of remedial measures to be undertaken are selected after consideration of the factors which influence the course of action (as noted in sections 5.1.1 through 5.1.4). As developed to date, remedial actions are aimed at one or more of the following: (1) reducing the source of formaldehyde, (2) reducing the penetration of formaldehyde into the living space, and (3) reducing the level of formaldehyde in the living space. Thus, the remedial measures described in the UFFI Centre Training Manual [123] include:

1. Reducing moisture levels in wet cavities through drying, and keeping the cavities as dry as possible. Examples include repair of roof and wall leaks, reducing air leaks into the walls, and maintaining low interior humidities.

2. Sealing air leakage paths both where outside air enters the structural walls, and where it finally enters the building. Sealing cracks and air leaks in and around the interior finish has been described as a simple and inexpensive step to help reduce the transport of formaldehyde and other gases from cavitywalls into the living space [123]. Effective sealing may eliminate the need for further remedial actions in many cases [123]. Examples of areas to be sealed include cracks or gaps between dry wall and trim; electrical outlets, switch plates and other fixtures; holes where pipes enter the wall; and cracks in interior finishes. The UFFI Centre Training Manual [123] gives drawings of areas of the house to be sealed.

3. Ventilation to reduce the formaldehyde gas concentration. Ventilation is carried out to dilute the concentration of formal- 
dehyde in the air of the living space by the addition of outside air into the residence. It may be accomplished by selective window openings or by the addition of a mechanical system (e.g. fans, furnace modifications) to blow outside air into the living space and exhaust inside air to the outdoors [123]. Techniques for mechanical ventilation systems described in the UFFI Centre Training Manual [123] include ventilation with pressurization and ventilation with heat exchangers. Ventilation is always carried out in conjunction with sealing of the walls of the residence.

4. Removal of the Urea-Formaldehyde Foam Insulation. This remedial action requires dismantling of a wall or part of its components to expose the foam. The insulation is then removed from the wall, components which remain are chemically treated, and the wall is reinsulated and restored to its original condition with tight sealing. Some of the materials taken from the wall during dismantling may have to be discarded because of damage or contamination. Removal is generally the most expensive of the remedial actions. The National Research Council, Canada, has indicated that among the remedial actions available to homeowners, removal should, in many cases, be the last resort [124]. Both the UFFI Centre Training Manual [123], and NRC Removal Document [124] provide extensive guidelines to be followed if removal is to be undertaken. The guidelines include considerations of the type of construction and whether the removal should be from the interior or exterior of the residence.

5. Safety Considerations During Remedial Actions. All documents describing remedial actions emphasize the safety considerations to be followed during the process. These safety considerations include the structural integrity of walls opened for foam removal, the wearing of protective equipment (e.g., masks, respirators) and clothing during removal, handling of chemicals, electrical hazards which may be encountered, protection of home furnishings during removal, and the clean-up and disposal of the removed foam $[123,124]$.

\subsection{EFFECTIVENESS OF REMEDIAL ACTIONS}

At present, few reports have been published concerning the effectiveness of remedial actions in reducing indoor formaldehyde levels attributed to the presence of urea-formaldehyde foam insulation. The UFFI Centre Assistance Program provides for formaldehyde measurements before and after remedial actions are undertaken [63]. Analysis of these data are ongoing. A number of research studies have been ongoing in Canada to investigate the effectiveness of remedial actions. The results of these studies have generally not yet been published. The remedial actions under investigation in Canada include [126]: removal; sealing and pressurization; pressurization, sealing, and ventilation; ventilation alone; the use of chemical scrubbers and filters; the use of ammonia gas to neutralize foam; and nondestructive methods to remove foam from wall cavities. 
One report has been published from Canada providing case histories of 137 residences ( 80 of which were in-depth) which contained urea-formaldehyde foam insulation [45]. The study was intended to provide practical experiences of the effectiveness of the guidelines given in the National Research Council, Canada, Building Practice Note 23 [26], and to provide information concerning the success of the remedial measures. It was found that building occupants could follow the guidelines given in Building Practice Note 23 for removal of foam and that they generally considered the foam removal to be successful. On the other hand, it was reported that "occupants have not felt that wall finishes were a sufficient barrier between them and UFFI." Thus, those wanting remedial action decided to remove the foam and not attempt to seal it in place.

Another finding of the study was that NRC recommendations for measuring and monitoring formaldehyde levels during the remedial action process were impracticable and could not be followed by the building occupants [45]. The report recommended that a readily-used, tamper-proof dosimeter be developed for homeowner use.

The UFFI Centre has indicated that the use of filters to reduce formaldehyde levels in indoor air has not been effective [123]. Limited data were obtained during this present study on the use of remedial measures such as charcoal filters, ammonia treatment, and ventilation of the exterior of the cavity-walls [127]. In this specific case, the use of charcoal filters and ammonia treatment reduced the level of formaldehyde in the indoor air immediately after installation, but the long-term effectiveness in maintaining reduced levels was not investigated.

A prelfminary laboratory study has been conducted in Canada to provide a qualitative evaluation of possible non-destructive techniques for removal of foam from wood frame cavity-walls [128]. The tests were intended to investigate whether practical means were available for foam removal to substitute for the labor intensive tasks of dismantling a wall or part of its components to expose the foam. The non-destructive methods included were mechanical breakdown of foam (e.g., rotating blades, drums, brushes), compressed air and vacuum removal, vibrating probes, and pressurized steam for foam hydrolysis. The results of the preliminary study were not considered promising without further evaluation of operating parameters, equipment, and operator safeguards. It was indicated that non-destructive removal of the foam did not appear to be practical unless equipment improvements were made. In one other case, preliminary investigations have been initiated to determine whether foam may be removed by non-destructive techniques from walls constructed of large hollow core bricks [69]. Using mechanical methods to breakdown the foam, the preliminary results have showed some promise, but further study is needed.

\subsection{RESEARCH ON UREA-FORMALDEHYDE FOAM INSULATION}

The National Research Council, Canada, is conducting an extensive research program to develop a technical data base on urea-formaldehyde foam insulation, its interaction with other building materials, and its effects on air quality, and to evaluate remedial measures by which foam effects on air quality can be 
reduced. This section presents a summary of the NRC research program. Areas of research within the NRC program include the following:

- Field investigations. Activities include identification and measurement of formaldehyde and other gases, particle sampling, problem assessment, and evaluation of remedial measures. Current activities have centered on residential construction, and it is expected that future work will shift to field investigation of commercial and institutional high-rise buildings.

- Remedial measures for residences. This activity includes the research on remedial measures. The research results will be used to provide technical support for the revision of the Canadian documents concerning remedial measures $[26,123]$.

- Remedial measures for highrise buildings. This area of research is focused on urea-formaldehyde foam insulation in highrise buildings, methods for reducing exposure of occupants to emission from the foam, and techniques for the isolation or removal of foam from these types of buildings.

- Materials properties and emissions. This research activity involves the determination of substances emitted by urea-formaldehyde foam insulation and factors which control the emissions. Also work is being undertaken to develop methods to measure the properties of the emissions.

- Methods to screen foam. This includes the development of methods of screening urea-formaldehyde foam insulation to allow quick determination of its quality and to identify potentially hazardous samples.

- Field measurements of emissions. Research is being undertaken to conduct field measurements of the concentrations of emissions from foam and to investigate the physical interactions between cavity spaces and living spaces and how the emissions pass from one to another.

- Techniques for measuring formaldehyde in air. This research focuses on the development of economical methods for measuring formaldehyde levels over prolonged periods in houses and the development of sophisticated measurement techniques for research purposes.

- Techniques for measuring other gases in air. This area of research concerns the development of economical methods for monitoring air contaminant levels over prolonged periods, the development of methods for monitoring the levels and rates of contaminant production, and the evaluation of chemical and mechanical sensors for the control of contaminants in indoor air.

- Techniques for measuring particles. This research is being conducted to determine and understand the mechanisms of the formation and release of particles from foams, and to develop protocols for the collection and characterization of these particles. 


\section{SUMMARY}

This study was a review of the use, properties, and performance of urea-formaldehyde foam as a thermal insulation. The review was based upon existing information of which a major source was the chemical and engineering literature. Building research organizations in foreign countries were contacted as another source of information on foam performance. Discussions were held with building researchers knowledgeable in the performance of urea-formaldehyde foam insulations. The information obtained during the review included standards for foam insulations, comments on the use of foam in foreign countries, reports on foam properties and performance, and documents describing remedial actions regarding formaldehyde release from foams.

The information received was collated and discussed in this report in major sections dealing with: standards and use of foam in other countries; factors affecting the performance of urea-formaldehyde foam insulations; offgassing and release of particulates; and remedial measures to reduce or eliminate formaldehyde release from foam into residences. The results of the study have shown that in the case of many performance factors, the available information is insufficient to predict the performance of the insulation in service. Although in the last few years many reports have been published on foam performance, they have indicated that performance may be variable and that reasons for the variability are not fully understood. Based on the study, the following summary of key findings concerning factors affecting performance as discussed in the report is presented:

- Formaldehyde release. Urea-formaldehyde foam insulations release formaldehyde under normal ambient conditions and for many months after application. In cases where formaldehyde measurements have been made, on the average, formaldehyde levels in homes with foam insulation are higher than those without foam. It is not disputed that many urea-formaldehyde foam insulated residences have relatively low formaldehyde levels. The extent of formaldehyde release is in general seasonal and may increase as temperature and humidity conditions increase. The level of formaldehyde in foam insulated residences is generally higher shortly after applications and decreases as time passes. The mechanism of formaldehyde release from foams is not totally understood.

In European countries (e.g., England and the Netherlands) where urea-formaldehyde foam insulation has experienced the most use, recommendations have been made to limit its use to masonry cavity walls having the inner leaf more impervious to Eormaldehyde transmission than the outer leaf. In these countries, it is generally recommended against insulating with foam light-frame wooden constructions having plasterboard-type walls because of the risk of formaldehyde entry to the residence. In addition, controls given in documents such as standards, codes of practice, and Agrément certificates are imposed with regard to material selection and installation. Nevertheless, at least one report from England has indicated that the level of formaldehyde in a residence after application is normally less than $0.5 \mathrm{ppm}$. 
Guidelines are not available in the United States for the selection and installation of urea-formaldehyde foam insulation in regard to the potential for formaldehyde to penetrate into the living space. In particular, the ASTM standard, as well as others, have no requirement for evaluating a foam sample with regard to long-term offgassing. Foam insulations have been used in many cases in wood-frame constructions in North America, which is a practice not considered acceptable in many European countries.

Guidelines have not been developed in the United States for the measurement of formaldehyde in foam-insulated residences. Guidelines are also not available concerning the measurement of formaldehyde levels in residences over time after foam installation. The practice of making one measurement at a particular point in time may not be reliable in defining the range of levels in the residence and whether the one sample is typical of the concentration present over time.

Remedial measures to reduce or eliminate formaldehyde levels in foam-insulated residences have been developed, particularly in Canada. These remedial measures concern reducing moisture in walls, sealing air leakage paths, ventilating the residence, and removing the foam. The National Research Council, Canada, has indicated that removal should, in many cases, be the last resort for remedial actions to reduce indoor formaldehyde levels. Extensive research is underway in Canada to determine the effectiveness of remedial actions.

Shrinkage. Linear shrinkage of urea-formaldehyde foam insulations in service has been found in field surveys to range from 1 to 10 percent and average 6 percent or more. Most standards have a requirement for maximum shrinkage under given test conditions. In the case of ASTM and some other standards, the maximum shrinkage is 4 percent. Such a requirement is for quality control purposes and not indicative of the amount of shrinkage which may be experienced in service. Studies have been conducted to determine the effect of shrinkage on the thermal efficiency of the insulated wall. These studies have provided evidence that linear shrinkage of about 6 percent can reduce the thermal efficiency by about 28 percent or more than that predicted on the basis of laboratory measurements of foam thermal conductivity. The Canadian and DOE standards, as well as the HUD Bulletin, all of which have been withdrawn, provided guidelines as to the reduction in thermal efficiency of foam-insulated walls due to shrinkage. The U.S. Federal Trade Commission requires that a disclosure statement on shrinkage or a reduction in the $\mathrm{R}$-value to account for shrinkage be made in advertisements, whenever ads for the product mention R-value.

- Cavity Filling. Urea-formaldehyde foam insulation is intended as a retrofit insulation for filling enclosed spaces of cavity walls. When properly applied, the semi-fluid foam can flow under pressure to fill a closed cavity completely. Proper application includes consideration of many factors such as the correct set time of the foam, proper hole spacings in cavities, obstructions in cavities, and the escape of air from cavities during their filling. Field studies have provided evidence that many cases of incomplete cavity fill have occurred. This has been especially the case in Canada, in spite of the previous existence of an application practice. At present, a standard practice 
for application does not exist in the United States. Codes of practice and guidelines for installation have been developed in some European countries where good workmanship during application is considered essential to satisfactory performance.

- Durability. The evidence in the literature describing the durability of urea-formaldehyde foams is contradictory. The foam has been described both as being expected to last as long as the building and also as having a short life in comparison to other building materials. Field observations have shown that in a number of cases installed foams have had no signs of significant deterioration, while in other cases significant deterioration, and in the extreme, disintegration has occurred. A methodology for evaluation of the durability of foams has not been developed for incorporation into ASTM and other standards. A key parameter affecting long-term performance is the resistance of foam to combined conditions of elevated temperature and humidity. Laboratory studies have indicated that the temperature-humidity resistance of foams may be variable, with some foams being more stable than others to such exposure.

- Effect on Other Building Materials. Reports in the literature describing the effect of foam on other building materials have provided examples of both acceptable performance and poor performance. In some cases, observations from field studies have shown little adverse effect on building materials such as gypsum plaster and wallboard, masonry materials, metals, paints and coatings, and wood. In other cases, reports have indicated that the presence of foam has contributed to problems with a masonry wall, metal wall ties, peeling of paint, and wooden wall members.

In regard to corrosion, metal objects have been observed in foam-insulated walls without signs of corrosion. In contrast, in other cases, the presence of the foam has been considered to be the cause of serious corrosion of electrical service boxes, ground wires attached to boxes, terminals of receptacles, galvanized ties, and steel studs. The variability in potential corrosiveness between different foams or foam applications has not been fully investigated in controlled laboratory studies. Some studies have indicated that corrosion rates vary depending upon test conditions and the type of metal. Field observations that some metal objects in contact with foam have experienced serious corrosion, while others have not, raise concerns about the adequacy of corrosion tests in the ASTM standard to distinguish between potentially corrosive and non-corrosive foams as used in service. The relationship of the performance of foam specimens in the corrosion tests given in the ASTM standard and foam performance in service has not been establisher.

With regard to wood, concerns have long been expressed that water present in freshly applied foam may not dry from the wall and result in damage to wooden members. The available evidence indicates that in most applications, the foam has dried, while in others drying did not occur as intended. Here, moistureinduced damage to wooden members has been observed. Acceptable practice in using foams requires that they not be applied in wall cavities from which the water cannot dry. Guidelines have not been developed in the United States regarding, application of foam into cavities to ensure that drying will satisfactorily occur. 
- Fungus Resistance. Laboratory tests have indicated that foams may .. resistant to some fungus species and not to others. Field observations have indicated cases where foam was observed in walls without fungus present, while in other installations fungus growth in foam-insulated cavities has been extensive. The incidence of the problem appears to be less than that of cases of excessive formaldehyde amission. Recent research findings from Canada have indicated a need to better define test methods and factors which affect fungus growth. Although the in-service performance of foams regarding fungus resistance may be variable, the ASTM standard does not contain a test requirement to evaluate this property of foams. The fungus resistance requirement was omitted in lieu of a caveat indicating that fungal growth was possible in cavities where foam remained wet for extended periods of time. No test method was included, since it was considered that an adequate test method for evaluating fungus resistance was not available.

- Release of Gases Other Than Formaldehyde and Particulates. Concerns have recently been raised that urea-formaldehyde foam insulations may release gases other than formaldehyde and particulates. Little information has been published in the literature on this subject. Some gases including acetaldehyde, benzaldehyde, phenol, cresols, and methylnaphthalenes may be emitted from foams. Small spheroids have been observed in microscopic examinations of foams. Research is underway, primarily in Canada, to develop test procedures for characterizing foams with regard to offgassing and particulate release.

- Quality Control of Component Materials. Methods to assure the quality of installed urea-formaldehyde foams should consider, among other parameters, the quality control of resins and foaming agents used to produce the insulations on-site. Records of formulation, production, storage, and on-site installation should be maintained as part of quality control procedures. The ASTM standard for foams does not in general contain quality control requirements for the component materials.

- Thermal Conductivity. Thermal conductivity values of foam specimens removed from walls of residences have been variable, ranging from about 0.22 to $0.33 \mathrm{Btu} \cdot \mathrm{in} / \mathrm{h} \cdot \mathrm{ft}^{2} \cdot{ }^{\circ} \mathrm{F}(0.032$ to $0.048 \mathrm{~W} / \mathrm{m} \cdot \mathrm{K})$ with an average value of $0.25 \mathrm{Btu} \cdot \mathrm{in} / \mathrm{h} \cdot \mathrm{ft}^{2} \cdot{ }^{\circ} \mathrm{F}(0.035 \mathrm{~W} / \mathrm{m} \cdot \mathrm{K})$. A design value for thermal conductivity for urea-formaldehyde foam insulations has not been included in the ASHRAE Handbook of Fundamentals, but guidelines are given. Laboratory measurements of thermal conductivity of foam specimens are not indicative of their thermal performance installed in walls because of unwanted heat loss due to shrinkage. Recommendations concerning design values of thermal conductivity should consider shrinkage effects. Many standards have included an effective thermal resistance to account for shrinkage effects. 


\section{REFERENCES}

1. Rossiter, Walter J. Jr, and Mathey, Robert G., "Criteria for Retrofit Materials and Products for the Weatherization of Residences," National Bureau of Standards (U.S.), Technical Note 982 (September 1978), 75 pages.

2. Petersen, Stephen R., "Retrofitting Existing Housing for Energy Conservation: An Economic Analysis," National Bureau of Standards (U.S.) Bldg. Sci. Ser. 64 (December 1974), 76 pages.

3. Seidel, Marquis R., Plotkin, Steven E., and Reck, Robert 0., "Energy Conservation Strategies," Environmental Protection Agency (U.S.) Report EPA - R5-73-021 (July 1973), page 7.

4. H.R. 6389 and H.R. 6391 - Urea-Formaldehyde Foam Insulation Hearing of the Committee on Small Business. House of Representatives (U.S.), Washington, D.C. (August 4, 1982), 149 pages.

5. Rossiter, Walter J. Jr., Mathey, Robert G., Burch, Douglas M., and Pierce, E. Thomas, "Urea-Formaldehyde Based Foam Insulations: An Assessment of Their Properties and Performance," National Bureau of Standards (U.S.), Technical Note 946 (July 1977), 92 pages.

6. "Urea-Formaldehyde Foam Insulation; Proposed Notice to Purchasers," Federal Register (U.S.), Vol. 45, No. 113 (June 10, 1980), page 39434.

7. "Ban of Urea-Formaldehyde Foam Insulation," Federal Register (U.S.), Vol. 47, No. 64 (April 2, 1982), pages 14366 - 14419.

8. "Ban of Urea-Formaldehyde Foam Insulation; Removal," Federal Register (U.S.), Vol. 48, No. 252 (December 30, 1983), pages 57478 and 57479.

9. "Report of the Hazardous Product Board of Review on Urea-Formaldehyde Foam Insulation," Consumer and Corporate Affairs (Canada), (October 5, 1982), 129 pages.

10. Meyer, B., "Urea-Formaldehyde Resins," Addison-Westley Publishing, Reading, MA, (1979).

11. Shirtliffe, C.J., "Presentation to the Expert Advisory Committee on UFFI," Hazardous Product Board of Review on Urea-Formaldehyde Foam Insulation, Consumer and Corporate Affairs (Canada), Report 34 (November 24,1980 ).

12. "Residential Conservation Service Program," Federal Register (U.S.), Vo1. 46, No. 17 (January 27, 1981), pages 8996 - 9005.

13. "Standard for: Thermal Insulation, Urea Based, Foamed In Situ," 51-GP-24M, December 1977, Canadian Government Specifications Board, Ottawa, Ontario, Canada. 
14. "Quality Requirements for UF Foam as Well as Procedural Guidelines for Insulating Hollow Walls with Such Foam," April 1982 Version, Bureau Kwaliteitsbewaking Spouwmuurvullingen, Bouwcentrum, Rotterdam.

15. "Specification for Urea-Formaldehyde (UF) Foam for Thermal Insulation of Cavity Walls," BS5617:1978, British Standards Institution.

16. West German Standard "Cellular Plastics as In Situ Cellular Plastics in Building: In Situ Cellular Plastics Produced from Urea-Formaldehyde (UF) Resin for Thermal Insulation; Application, Properties, Execution, Testing," DIN 18-159, Part 2, (June 1978).

17. "Standard Specification for Urea-Formaldehyde-Based Foamed-in-Place Insulation," ASTM Designation C 951-83, 1984 Annual Book of ASTM Standards, Section 4, Vol. 4.06, American Society for Testing and Materials, Philadelphia, PA.

18. "Interim Standard for Urea-Formaldehyde Foamed-in-Place Insulation," 10 CFR Part 456 (Section 456.810), Department of Energy (U.S.), Federal Register, Vo1. 45, No. 188 (September 25, 1980), pp.63793-63810.

19. "Thermal Insulation, Urea-Based, Foamed in Place," Use of Materials Bulletin No. 74, Department of Housing and Urban Development (U.S.) (October 13, 1977), 21 pages.

20. "Provisional Standard for: The Installation of Foamed-In-Situ Urea Based Insulation, 51-GP-22MP, December 1977, Canadian Government Specifications Board, Ottawa, Ontario, Canada.

21. "Code of Practice for Thermal Insulation of Cavity Walls (with Masonry Inner and Outer Leaves) by Filling with Urea-Formaldehyde (UF) Foam," BS 5618:1978, British Standards Institution.

22. "Residential Conservation Service Program," 10 CFR Part 456, Department of Energy, Office of Conservation and Solar Energy, Federal Register, Vol. 45, No. 188 (September 25, 1980), pp. 63786-63791.

23. "Feasibility of a Standard," 16 CFR Part 1306 (Section 5), Ban of UreaFormaldehyde Foam Insulation, Consumer Product Safety Commission, Federal Register, Vo1. 47, No. 64 (Apri1 2, 1982), pp. 14401-14409.

24. Long, K. R. and Schutte, W. C., "Problems Associated with the Use of Urea-Formaldehyde Foam for Residential Insulation Part IV: The Relevance of Materials Standards to Problems Associated with the Use of UreaFormaldehyde Foam Insulation," ORNL/sub-7559/4, Oak Ridge National Laboratory, February 1981.

25. Pratt, N., Transcript, Technical Workshop on Formaldehyde, Vol. II, Consumer Product Safety Commission (U.S.) (April 10, 1980), p. 189 . 
26. Bowen, R. P., Shirtliffe, C. J., and Chown, G. A., "Urea-Formaldehyde Foam Insulation: Problem Identification and Remedial Measures for Wood-Frame Construction," National Research Council (Canada), Building Practice Note 23 (August 1981), 66 pages.

27. Rossiter, W. J., Jr., Ballard, D. B., and Sleater, G. A., "Elevated Temperature and Humidity Effects on Urea-Formaldehyde Foam Insulations Observed by Scanning Electron Microscopy," ASTM STP 789 (1983), pp. 665-687.

28. Rossiter, Nalter J. NBS, unpublished results.

29. "Formaldehyde Vapor from Urea-Formaldehyde Foam Insulation," Building Research Establishment (U.K.), Information Paper 25/82 (November 1982), 2 pages.

30. Dunlop, L., "The Use of Urea-Formaldehyde Foam Insulation," Experimental Building Station (Australia), Technical Record 472 (October 1981), 47 pages.

31. "Cavity Insulation," Digest 236, Building Research Station, Garston, Watford, England (April 1980), 4 pages.

32. "Urea-Formaldehyde Foam Cavity Wall Insulation: Reducing Formaldehyde Vapor in Dwellings," Building Research Establishment (U.K.), Information Paper 7/84 (March 1984), 2 pages.

33. Osborn, S. W., "Urea-Formaldehyde Foam Insulation Study," Franklin Research Center, Prepared for Oak Ridge National Laboratory (U.S.), F-C5316-01 (January 1981).

34. Kokko, E., Poijarvi, H., Sarimmaa, J., and Waananen, M., "Directions for Correction of Deficiencies in Thermal Insulation in Buildings Through the Use of Urea-Formaldehyde Foam," Technical Research Center (Finland), Report 26 (August 1976), 26 pages.

35. Fleury, Gerard, CSTB, France, Personal Communication.

36. Barrett, P. V. L., "Formaldehyde and Urea-Formaldehyde Cavity Wall Insulation," Structural Survey, Vol. 2, No. 4 (1984), pp. 369-373.

37. Hawthorne, A. R. and Gammage, R. B., "Formaldehyde Release From Simulated Wall Panels Insulated with Urea-Formaldehyde Foam Insulation," J. Air Pollution Control Association, Vol. 32, No. 11 (November 1982), pp. $1126-1131$.

38. Vinieratos, E. R. and Verschoor, J. D., "Influence of Insulation Deficiencies on Heat Loss in Walls and Ceilings," ASTM STP 718, McElroy, n. L. and Type, R. P. (eds.), American Society for Testing and Materials (1980), pp. 142-159. 
39. Draft Document on the Removal of Urea-Formaldehyde Foam Insulation, National Research Council (Canada), in review.

40. Bowles, A. M. and Shirtliffe, C. J., "Development of a Canadian Standard for Urea-Formaldehyde Thermal Wall Insulation," ASTM STP 718, McElroy, D. L. and Tye, R. P. (eds.), American Society for Testing and Materials (1980), pp. 361-394.

41. Tsongas, George A., Ode11, F. Glen, and Thompson, Jaines C., "A Field Study of Moisture Damage in Walls Insulated Without a Vapor Barrier," Proceedings of the ASHRAE/DOE-ORNL Conference on Thermal Performance of the Exterior Envelopes of Buildings, ASHRAE SP 28 (December 1979), pp. 801-815.

42. Weidt, John L., Saxler, Robert J., and Rossiter, Walter, J., Jr., "Field Investigation of the Performance of Residential Retrofit Insulation," National Bureau of Standards (U.S.), Tech. Note 1131 (September 1980), 67 pages.

43. Spinney, Stu and Weidt, John, "Minnesota Retrofit Insulation In Situ Test Program," Minnesota Energy Agency, St. Paul, MN (May 1978), 134 pages.

44. Shirtliffe, C. J., Transcript, Technical Workshop on Formaldehyde, Vol. II, Consumer Product Safety Commission (U.S.), (April 10, 1980), pp. 74-90.

45. Clerk, Mark, "Investigation of the Circumstances Surrounding Specific Houses Containing Urea-Formaldehyde Foamed-in-Place Insulation and the Success of Any Remedial Measures," Prepared for the National Research Council (Canada).

46. "Interim Standard Practice for the Installation of Urea-Formaldehyde Foamed-in-Place Insulation," Department of Energy (U.S.), Federal Register, Vol. 45, No. 188 (September 25, 1980), pp. 63802-63810.

47. "Standard Practice for Developing Accelerated Tests to Aid Prediction of the Service Life of Building Components and Materials," ASTM E 632-82, ASTM, Philadelphia, PA (1982).

48. Wulkan, E. K. H., "Practical Experiences with Urea-Formaldehyde Foam Insulation of Cavity Walls," Plastica, Vol. 30, No. 8 (August 1977), pages 242-249.

49. Chown, G. A., Bowen, R. P., and Shirtliffe, C. J., "Urea-Formaldehyde Foam Insulation," National Research Council (Canada), Building Practice Note 19, (April 1981), 10 pages.

50. Young, Judith, National Research Council (Canada), Personal Communication.

51. "Ban of Urea-Formaldehyde Foam Insulation," Federal Register (J.S.), Vo1. 47, No. 64, (April 2, 1982), page 14396. 
52. Noury, J. P. and Fleury, G., "Improvement of Thermal Insulation for Cavity Walls," Centre Scientifique et Technique du Ratiment (France), (October 5, 1976).

53. Dosterhoff, W., "Kruizemuntstraat Apeldoorn Insulation Project: An Analysis of the Effect of Insulation on Gas Consumption," SKOOP Conference, Adeldoorn, Holland (May 16, 1975), 13 pages.

54. Van Es, J. C., "Fuel Conservation as a Result of Improvement in the Thermal Insulation of Existing Single-Family Dwellings," Bouwcentrum (Holland), Report No. 4813 (December 1975), 17 pages.

55. Burch, D. M. and Hunt, C. M., "Retrofitting on Existing Wood Frame Residences for Energy Conservation - An Experimental Study," National Bureau of Standards (U.S.), Bldg. Sci. Ser. 105 (July 1978), 82 pages.

56. Timm, W. A., Communication at ASTM UF Foam Task Group Meeting.

57. "Corrosiveness of Urea-Formaldehyde Foam Insulation," Department of Public Works (Canada), Research and Development Laboratories, Ottawa, Ontario (November 1976).

58. Weil, R., Graviano, A., and Sheppard, K., "Corrosion Testing of UreaFormaldehyde Foam Insulating Material," nak Ridge National Laboratory Report, ORNL/Sub-7556/2 (September 1980), 30 pages.

59. Clifton, J. R., Beausoliel, R. W., and Meese, W. J., "Effects of Thermal Insulation Penetrating Electrical Boxes," ASTM STP 779, Lieff, M. and Trechse1, H. R. (eds.), American Society for Testing and Materials (1982), pp. 241-261.

60. Kouhia, I., Technial Research Center of Finland, Personal Communication.

61. Kokko, E., Kouhia, I., Poijarvi, H., and Waananen, M., "UF Foam and the Effects of Its Injection on the Heat Transfer Coefficient in old Wooden Buildings," Technical Research Center (Finland), Report 27 (1976), 113 pages.

62. State Institute for Construction Research (Sweden), Classification UDK 699.86, Publication No. 1963:4.

63. Hall, Stephen, UFFI Centre (Canada), Personal Communication.

64. "Moisture Induced Problems in NHA Housing--Analysis of Field Survey Results and Projections of Future Problems," Canadian Mortgage and Housing Corporation, Part 1 (June 1983), 108 pages.

65. Birky, Merritt, formerly NBS Center for Fire Research, Personal Communication. 
66. Paabo, M., Birky, M. M., and Womble, S. E., "Analysis of Hydrogen Cyanide in Fire Environments," J. Combustion Toxicology, Vol. 6 (May 1979), pp. 99-108.

67. "Determination of the Resistance of Urea-Formaldehyde Foam to Fungal Attack", The Cavity Foam Bureau (J.K.), Report 13/02 (January 23, 1978), 2 pages; and Report 13/38 (April 20, 1979), 4 pages.

68. Bech-Andersen, Joergen, "The Influence in Vivo of Serpula Lacrymans on Insulating Materials as Carbamidfoam, Glass, and Stonewood," Proceedings, 3rd International Mycological Congress, Tokyo (August 28 - September 3, 1983), page 385 .

69. Shirtliffe, C. J., National Research Council (Canada), Personal Communication.

70. "Cavity-Insulation," Building Research Establishment Digest 236, Building Research Station (J.K.) (April 1980), 4 pages.

71. Whiteside, D., Newman, A. J., Kloss, P. B., and Willis, W., "Full-scale Testing of the Resistance to Water Penetration of Seven Cavity Fills," Building and Environment, Vol. 15 (1980), pp. 109-118.

72. Newman, A. J., Whiteside, D., Kloss, P. B., and Willis, W., "Full-scale Water Penetration Tests on Twelve Cavity Fills - Part I. Nine Retrofit Fills," Building and Environment, Vol.17, No. 3 (1982), pp. 175-191.

73. Newman, A. J., Whiteside, D., and Kloss, P. B., "Full-scale Water Penetration Tests on Twelve Cavity Fills - Part II. Three Built-In Fills," Building and Environment, Vol. 17, No. 3 (1982), pp. 193-207.

74. Newman, A. J. and Whiteside, D., "Water and Air Penetration Through Brick Walls - A Theoretical and Experimental Study," Trans. J. British Ceramics Society, Vol. 80 (1981), pp. 17-26.

75. Timm, William and Smith, Patti M., "Cause and Effect of Shrinkage in Urea-Based Foams," J. Thermal Insulation, Vol. 3 (April 1980), p. 217.

76. Reference No. 5 cited in Timm, William and Smith, Patti M., "Cause and Effect of Shrinkage in Urea-Based Foams," J. Thermal Insulation, Vo1. 3 (April 1980), p. 217.

77. Firstman, Sidney I., "Thermal Properties of Shrinkage-Created Air Gaps in Foam Insulated Walls," Science Applications, El Segundo, CA (May 16, 1977), 17 pages.

78. Peavy, B., National Bureau of Standards, Personal Communication.

79. Committee on Urea-Formaldehyde Thermal Insulation, CGSB (Canada), 1105-51-8P110, cited in Federal Register (U.S.), Vol. 45, No. 188 (September 25,1980 ), page 63790 . 
80. Tye, R. P. and Desjarlais, A. O., "Performance Characteristics of Foamed-in-Place Urea-Formaldehyde Insulation," Oak Ridge National Laboratory (U.S.), ORNL-Sub-78/86993/1 (June 1981), 36 pages.

81. McFadden, Peter W., Azar, Kaveh, and Zebrowski, Thaddeus J., "The Thermal Resistance of In-situ Urea-Formaldehyde Foam Insulation," J o Thermal Insulation, Vol. 6 (October 1982), pp. 63-74.

82. "Labeling and Advertising of Home Insulation," Final Staff Report, Federal Trade Commission (U.S.) (July 1978), pp. 44-60.

83. "Trade Regulations: Labeling and Advertising of Home Insulation," Federal Register (U.S.), Vo1.44, No. 167 (August 27, 1979), pp. 50218-50245.

84. Allan, G. Graham, Dutkiewicz, Jacek, and Gilmartin, Ear1 J., "Long-Term Stability of Urea-Formaldehyde Foam Insulation," Environmental Science and Technology, Vol. 14 (1980), pp. 1235-1240.

85. Dutkiewicz, Jacek, "Hydrolytic Degradation of Cured Urea-Formaldehyde Resin," J. Applied Polymer Science, Vol 28 (1983), pp. 3313-3320.

86. ASHRAE Handbook of Fundamentals, American Society of Heating, Refrigerating, and Air-Conditioning Engineers, Inc., Atlanta, GA (1981).

87. "Formaldehyde - An Assessment of Its Health Effects," Committee on Toxicology, National Academy of Sciences (U.S.) (March 1980), 44 pages.

88. "Formaldehyde: Review of Scientific Basis of EPA's Carcinogenic Risk Ássessment," Hearing of the Committee on Science and Technology, House of Representatives (U.S.), Washington, DC (May 20, 1982), 793 pages.

89. "Update on Toxicity of Urea-Formaldehyde Foam Insulation (UFFI)," Health and Welfare (Canada), Information Letter (August 12, 1983), 4 pages.

90. Nantel, A., "UFFI-Related Studies in Quebec," Paper presented at the UFFI Research Update, Ottawa, Canada (May 17-18, 1983).

91. Sereda, Peter, National Research Council (Canada), Personal Communication.

92. Molhave, Lars, "Indoor Air Pollution Due to Organic Gases and Vapors of Solvents in Building Materials," Envrionment International, Vo1. 8 (1982), pp. 117-127.

93. Miksch, R. R., Hollowe11, C. D., and Schmidt, H. E., "Trace Organic Chemical Contaminants in office Spaces," Environment International, Vol. 8, (1982), pp 129-137.

94. "Final Report of the National Testing Survey Conducted by the UreaFormaldehyde Foam Insulation Information and Coordination Centre," UFFI Centre (Canada) (September 1983), 70 pages. 
95. Schutte, W. C., Cole, R. S., Frank, C. W., and Long, K. R., "Problems Associated with the Use of Urea-Formaldehyde Foam for Residential Insulation, Part III: Residential Studies in Colorado and Wisconsin," Univ. Iowa, prepared for Oak Ridge National Laboratory (U.S.), ORNL/Sub-7559/3 (February 1981), 32 pages.

96. "Status Report on the Indoor Air Quality Monitoring Study in 40 Homes," Consumer Product Safety Commission (March 16, 1984).

97. Cohn, Murray S., "Revised Carcinogenic Risk Assessment for Urea-Formaldehyde Foam Insulation: Estimates of Cancer Risk Due to Inhalation of Formaldehyde Released by UFFI," Consumer Product Safety Commission (U.S.), (October 26, 1981), 227 pages.

98. Matthews, T. G., Reed, T. J., Tromberg, B. R., and Hawthorne, A. R., "Modeling and Testing Emission Characteristics of Pressed-Wood Products," Oak Ridge National Laboratory (U.S.), Prepared for Consumer Product Safety Commission, CPSC-IAG-82-1297 (October - November 1983), 30 pages.

99. "Formaldehyde and Other Aldehydes," Committee on Aldehydes, National Research Council (U.S.), National Academy Press, Washington, D.C., (1981).

100. Kennedy, Eugene R., Teass, Alexander W., and Gagnon, Yvonne T., "Industrial Hygiene Sampling for Formaldehyde - Past and Present," NIOSH (U.S.), (draft March 22, 1984), 17 pages.

101. Shirtliffe, C. J., Rousseau, M. Z., Young, J. C., Sliwinski, J. F., and Sim, P. G., "Formaldehyde Measurements in Canadlian Homes Using Passive Dosimeters," Proceedings Am. Chem. Soc., St Louis (April 1984), in publication.

102. UFFI Research Update, Nationa1 Research Council (Canada) (May 17-18, 1983).

103. Matthews, T. G. and Howe11, T. C., "Visual Colorimetric Formaldehyde Screening Analysis for Indoor Air," APCA Journal, Vol. 31, No. 11 (November 1981), pp. 1181-1184.

104. Matthews, T. G., Hawthorne, A. R., Howel1, T. C., Metcalfe, C. E., and Gammage, R. B., "Evaluation of Selected Monitoring Methods for Formaldehyde in Domestic Environments," Environment Internationa1, Vol. 8 (1982), pp. 143-151.

105. Matthews, T. G., "Evaluation of Modified CEA Instruments, Inc. Model 555 Analyzed for the Monitoring of Formaldehyde Vapor in Domestic Environments," American Industrial Hygiene Association Journal, Vol. 43 (August 1982), pp. 547-552.

106. "Formaldehyde Gas Measurement," Transcript of NRC-UFFI Research Update, Tuesday, May 17, 1983, Nationa1 Research Council (Canada), pages 151-263. 
107. "Testing Protocol for the Full-Scale Testing of Homes in Canada Insulated with Urea-Formaldehyde Foam," UFFI Centre (Canada) (January 25, 1983), 38 pages.

108. Allan, G. Graham, Transcript, Technical Workshop on Formaldehyde, Vol. II, Consumer Product Safety Commission (U.S.) (April 10, 1980), pp. 186-187.

109. Long, K. R., Pierson, D. A., Brennan, S. T., and Frank, C. W., "Problems Associated With the Use of Urea-Formaldehyde Foam for Residential Insulation. Part I: The Effects of Temperature and Humidity on Formaldehyde Release from Urea-Formaldehyde Foam Insulation," Univ. Iowa, Prepared for Oak Ridge National Laboratory (U.S.), ORNL/SUB-7559/1 (September 1979), 89 pages.

110. Shutte, W. C., Cole, R. S., Frank, C. W., and Long, K. R., "Problems Associated with the Use of Urea-Formaldehyde Foam for Residential Insulation. Part II: The Effects of Temperature and Humidity on Free Formaldehyde, Extractable Formaldehyde, Formaldehyde Fmission, and Physical Characteristics of the Foam," Univ. Iowa, Prepared for Oak Ridge National Laboratory (U.S.), ORNL/SUB/7559//2 (February 1981), 80 pages.

111. Pratt, N., Transcript, Technical Workshop on Formaldehyde, Vol. II, Consumer Product Safety Commission (J.S.) (Apri1 10, 1980), pp. 9-17.

112. Tomita, Brunchiro, Transcript, Technical Workshop on Formaldehyde, Vol. II, Consumer Product Safety Commission (U.S.) (April 10, 1980), pp. 22-34.

113. Rybicky, Jaroslav and Kambauis, Stamatis M., "Determination of Rate of Formaldehyde Release from Urea-Formaldehyde and Phenol Formaldehyde Foams," J. Thermal Insulation, Vol. 4 (January 1981), pp. 171-181.

114. Rybicky, Jaroslav and Kambauis, Stamatis, M., "Reichhold Box Method for the Determination of Formaldehyde Release from Urea-Formaldehyde and Phenol Formaldehyde Foams: Kinetic Treatment," J. Thermal Insulation, Vol. 5 (July 1981), pp. 3-11.

115. Timm, William and Smith, Patti, M., "Test for Formaldehyde Off-Gassing Rates from Insulation and Other Building Materials," J. Thermal Insulation, Vol. 4 (October 1980), pp. 137-153.

116. Tsuchiya, Y., "Instrument APCI/MS/MS for Gas Analysis." NRC-UFFI Research Update, National Research Council (Canada) (May 17, 1983), pp. 64-68.

117. Barrett, Peter, "UF Foam - The Current Situation," Insulation (October 1982), pp. 12-13.

118. Timm, William and Smith, Patti, M., op. cit., p. 142.

119. Rousseau, Madeleine, National Research Council, (Canada), Personal Communication. 
120. Weber, J.P., "Respirable UFFI Particles," NRC-UFFI Research Update, National Research Council (Canada) Vol. I (May 17, 1983), pp. 40-47.

121. Nantel, A., "UFFI Related Studies in Quebec," NRC-UFFI Research Update, National Research Council (Canada), Vol. II (May 18, 1983), pp. 527-536.

122. "Assistance Program for UFFI Homeowners-Guide," UFFI Centre (Canada).

123. "Training Manual on: Corrective Measures for Residences Insulated with Urea-Formaldehyde Foam Insulation (UFFI)," UFFI Centre (Canada), Specification 82-03R (February 1983).

124. Removal Document for Urea-Formaldehyde Foam Insulation, National Research Council (Canada), in review.

125. Dunlap, L., "Urea-Formaldehyde Foam Insulation: Problem Identification and Remedial Measures," Experimental Building Station (Australia), Technical Record 488 (November 1982), 24 pages.

126. Sessions on "Remedial Measures" and "Field Observations," NRC-UFFI Research Update, National Research Council (Canada) (May 18, 1983), pp. 267-495.

127. Long, Keith, Univ. Iowa, Personal Communication.

128. Alderson, W., "Non-destructive Removal Methods," NRC-UFFI Research Update, National Research Council (Canada), Vol. II (May 18, 1983), pp. 365-372. 


\section{ACKNOWLEDGMENTS}

This study was sponsored by the U.S. Department of Energy (DOE). W. Gerken, DOE, provided technical liaison to NBS. J. Heldenbrand, NBS, provided technical liaison to DOE. Their support and encouragement throughout the study were gratefully appreciated.

Special thanks and appreciation are extended to C. Shirtliffe, National Research Council, Canada, for his valuable assistance during the study. The authors appreciate his time spent in discussing the performance of urea-formaldehyde foam insulations, measurement methods for formaldehyde in residences, and the ongoing studies of the NRC UFFI research group. His assistance in making arrangements to visit NRC researchers as well as others in Canada was also appreciated.

The authors also thank those members of the NRC UFFI research group who spent time with them in discussing their work. These individuals are R. Dussault, S. Rolfe, M. Rousseau, P. Sereda, G. Sim, J. Svec, and J. Young. Thanks are also extended to S. Hall, UFFI Centre, Canada, for his discussions of the UFFI Centre program and measurements of formaldehyde and moisture content of walls conducted in the program.

The authors also appreciate the review, and noteworthy comments and suggestions concerning this report which were provided by their NBS colleagues, D. Burch, G. Frohnsdorff, D. Gross, and P. McNall. Sincere thanks are also expressed to those outside of NBS who provided many valuable comments in reviewing a draft of this report: W. Gerken (DOE), S. Hall (UFFI Centre, Canada), K. Long (Univ. of Iowa), D. McElroy (Oak Ridge National Laboratory), M. Rousseau (National Research Council, Canada), and C. Shirtliffe (National Research Council, Canada). 
NBS-114A (REV. 2-8C)

\begin{tabular}{c|c|c|c}
$\begin{array}{c}\text { U.S. OEPT. OF COMM. } \\
\text { BIBLIOGRAPHIC DATA } \\
\text { SHEET (See instructions) }\end{array}$ & $\begin{array}{l}\text { 1. PUBLICATION OR } \\
\text { REPORT NO. } \\
\text { NBS/TN-1210 }\end{array}$ & 2. Performing Organ. Report No. & 3. Publication Date \\
March 1985
\end{tabular}

4. TITLE AND SUBTITLE

Urea-Formaldehyde Foam Insulations: A Review of Their Properties and Performance

\section{5. $\operatorname{AUTHOR}(S)$}

Walter J. Rossiter, Jr, and Robert G. Mathey

6. PERFORMING ORGANIZATION (If joint or other than NBS, see instructions)

NATIONAL BUREAU OF STANDARDS

DEPARTMENT OF COMMERCE

GAITHERSBURG, MD 20899

7. Contract/Grant No.

8. Type of Report \& Period Covered

Final

9. SPONSORING ORGANIZATION NAME AND COMPLETE ADDRESS (Street, City. State, ZIP)

Office of Conservation and Renewable Energy

Department of Energy

1000 Independence Avenue, S.W.

Washington, DC 20585

10. SUPPLEMENTARY NOTES

[Document describes a computer program; SF-185, FIPS Software Summary, is attached.

11. ABSTRACT (A 200-word or less factual summary of most significant information. If document includes a significant bibliography or literature survey. mention it here)

Urea-formaldehyde foam insulation was commonly used in the mid-to-1ate 1970s for retrofitting the sidewalls of residences. Many reports describing the use of this material in buildings have been published. This report presents a review of the properties and performance of urea-formaldehyde foams pertinent to their use as thermal insulation for bulldings. The review is based primarily on existing published literature. The factors affecting the performance of these insulations are 1 isted and discussed. Included anong these factors are durability, effect on energy conservation, effect on other building materials, fungus resistance, shrinkage, and temperature and humidity effects on foam.

A key lssue involving the use of urea-formaldehyde foam insulation is its release of formaldehyde, other gases, and particulates into the air of residences. Information concerning the release of these agents is summarized. The literature evidence indicates that where formaldehyde measurements have been made, on the average, formaldehyde levels in homes with foam insulation are higher than those without foam. The mechanism of formaldehyde release from foams is not totally underslood. A review of remedial actions which may be taken to reduce or eliminate formaldehyde release from foams into residences is given. The information concerning the remedial actions discussed are those primarily being used in Canadi. In addition, standards for urea-formaldehyde foam insulations developed in North Anerlca and Europe were reviewed and the material property requirements tabulated. The standards do not contain requirements pertainfng to the long-term release of formaldehyde from these foam insulations.

12. KEY WORDS (Six to twelve entries; alphabetical order; capitalize only proper names; and separate key words by semicolons) cellular plastics; energy conservation; formaldehyde; performance factors; remedial actions; retrofit; standards; thermal insulation; urea-formaldehyde foam.

13. AVAILABILITY

X] Unlimited

For Official Distribution. Do Not Release to NTIS

[X] Order From Superintendent of Documents, U.S. Government Printing Office, Washington, D.C. 20402.

[ Order From National Technical Information Service (NTIS), Springfield, VA. 22I6I
14. NO. OF PRINTED PAGES

70

15. Price 

1 


\section{Technical Publications}

\section{Periodical}

Journal of Research-The Journal of Research of the National Bureau of Standards reports NBS research and development in those disciplines of the physical and engineering sciences in which the Bureau is active. These include physics, chemistry, engineering, mathematics, and computer sciences. Papers cover a broad range of subjects, with major emphasis on measurement methodology and the basic technology underlying standardization. Also included from time to time are survey articles on topics closely related to the Bureau's technical and scientific programs. As a special service to subscribers each issue contains complete citations to all recent Bureau publications in both NBS and non-NBS media. Issued six times a year.

\section{Nonperiodicals}

Monographs-Major contributions to the technical literature on various subjects related to the Bureau's scientific and technical activities.

Handbooks-Recommended codes of engineering and industrial practice (including safety codes) developed in cooperation with interested industries, professional organizations, and regulatory bodies.

Special Publications-Include proceedings of conferences sponsored by NBS, NBS annual reports, and other special publications appropriate to this grouping such as wall charts, pocket cards, and bibliographies.

Applied Mathematics Series-Mathematical tables, manuals, and studies of special interest to physicists, engineers, chemists, biologists, mathematicians, computer programmers, and others engaged in scientific and technical work.

National Standard Reference Data Series-Provides quantitative data on the physical and chemical properties of materials, compiled from the world's literature and critically evaluated. Developed under a worldwide program coordinated by NBS under the authority of the National Standard Data Act (Public Law 90-396).

NOTE: The Journal of Physical and Chemical Reference Data (JPCRD) is published quarterly for NBS by the American Chemical Society (ACS) and the American Institute of Physics (AIP). Subscriptions, reprints, and supplements are available from ACS, 1155 Sixteenth St., NW, Washington, DC 20056.

Building Science Series-Disseminates technical information developed at the Bureau on building materials, components, systems, and whole structures. The series presents research results, test methods, and performance criteria related to the structural and environmental functions and the durability and safety characteristics of building elements and systems.

Technical Notes-Studies or reports which are complete in themselves but restrictive in their treatment of a subject. Analogous to monographs but not so comprehensive in scope or definitive in treatment of the subject area. Often serve as a vehicle for final reports of work performed at NBS under the sponsorship of other government agencies.

Voluntary Product Standards-Developed under procedures published by the Department of Commerce in Part 10, Title 15, of the Code of Federal Regulations. The standards establish nationally recognized requirements for products, and provide all concerned interests with a basis for common understanding of the characteristics of the products. NBS administers this program as a supplement to the activities of the private sector standardizing organizations.

Consumer Information Series-Practical information, based on NBS research and experience, covering areas of interest to the consumer. Easily understandable language and illustrations provide useful background knowledge for shopping in today's technological marketplace.

Order the above NBS publications from: Superintendent of Documents, Government Printing Office, Washington, DC 20402.

Order the following NBS publications-FIPS and NBSIR's-from the National Technical Information Service, Springfield, VA 22161.

Federal Information Processing Standards Publications (FIPS PUB)-Publications in this series collectively constitute the Federal Information Processing Standards Register. The Register serves as the official source of information in the Federal Government regarding standards issued by NBS pursuant to the Federal Property and Administrative Services Act of 1949 as amended, Public Law 89-306 (79 Stat. 1127), and as implemented by Executive Order 11717 (38 FR 12315, dated May 11, 1973) and Part 6 of Title 15 CFR (Code of Federal Regulations).

NBS Interagency Reports (NBSIR)-A special series of interim or final reports on work performed by NBS for outside sponsors (both government and non-government). In general, initial distribution is handled by the sponsor; public distribution is by the National Technical Information Service, Springfield, VA 22161, in paper copy or microfiche form. 
U.S. Department of Commerce National Bureau of Standards

Gaithersburg, MD 20899

\section{Official Business}

Penalty for Private Use $\$ 300$ 